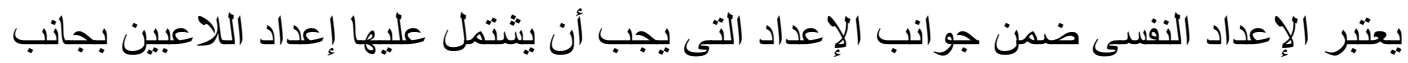

الإعداد البدنى و المهارى و الخططى لإحداث التنمية الثناملة للاعبين للوصول بهم إلى المستويات

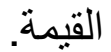

وتزداد أهمبة الإعداد النفسى للاعبى الأنشطة النزالية حيث أن المبار اة فى تلك الأنشطة

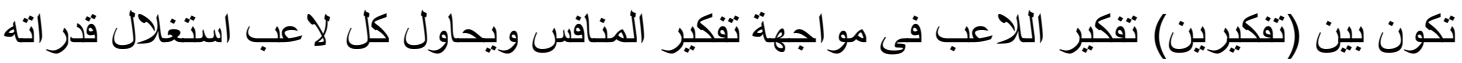

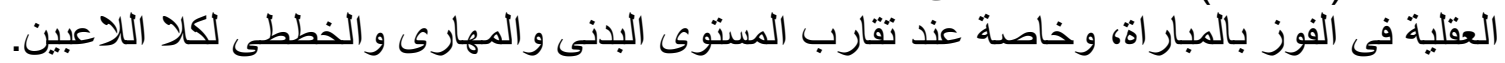

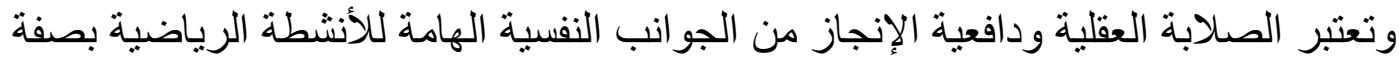

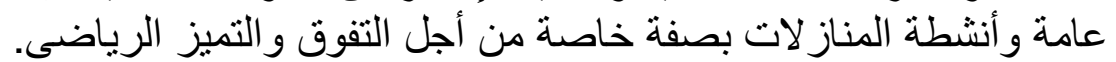

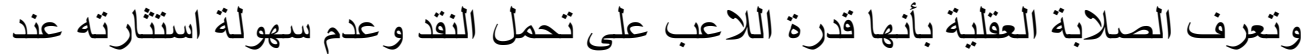

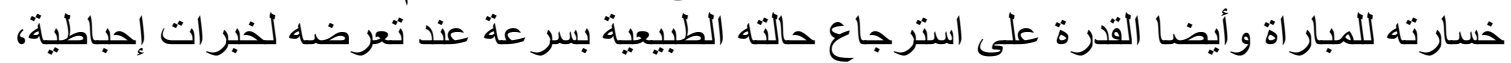

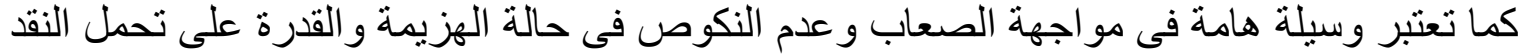
دون فقد التركيز أو الثقة بالنفس (10 (10 : 10).

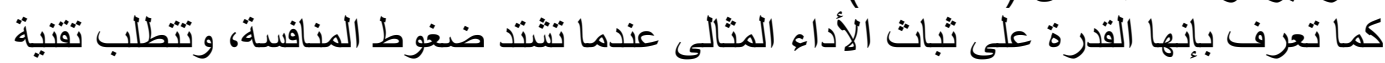

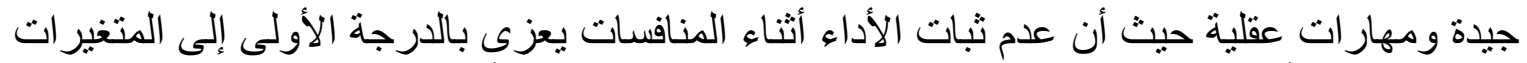

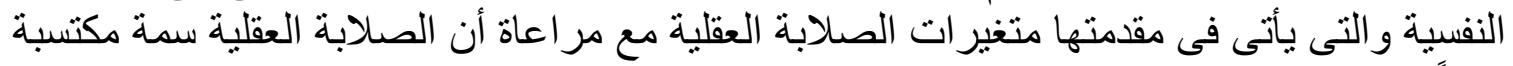

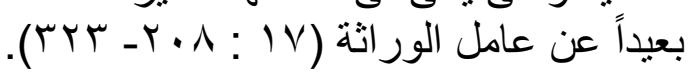

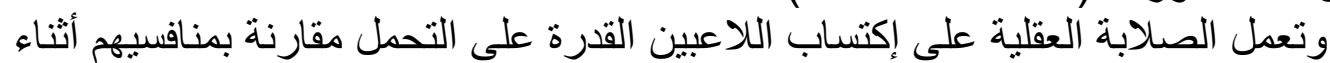
التنافس الرياضى أو التدريب أو أسلوب الحياة من خلال تطوير التركيز والثقة والثبات و العمل تحت

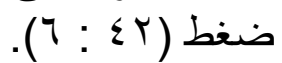

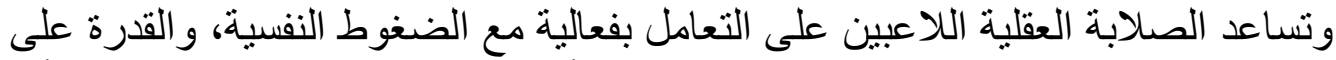

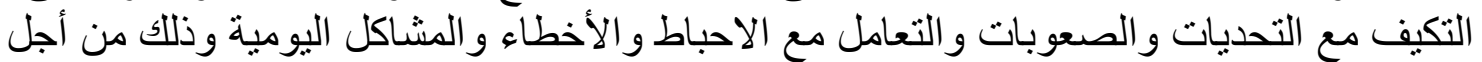

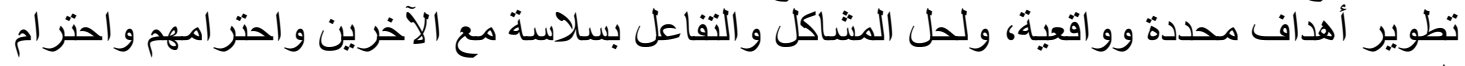

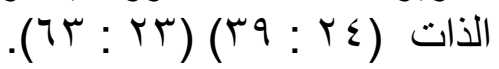

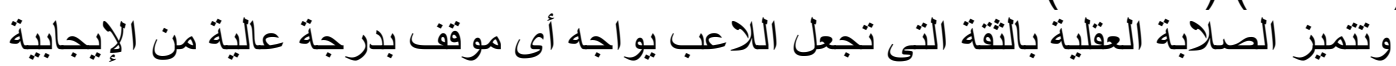

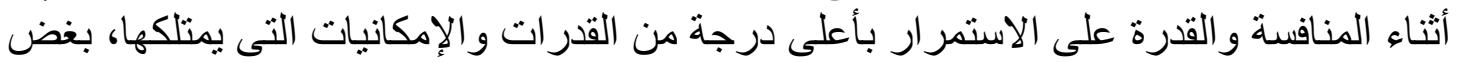

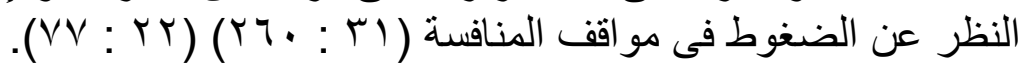

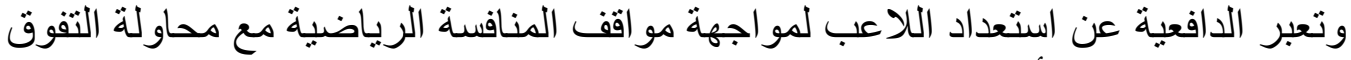

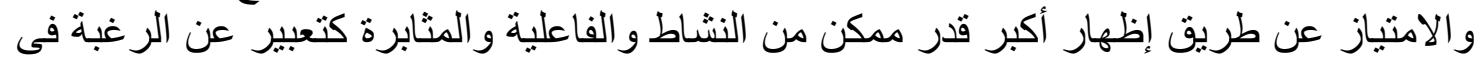

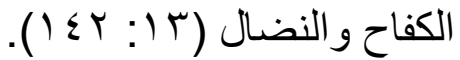

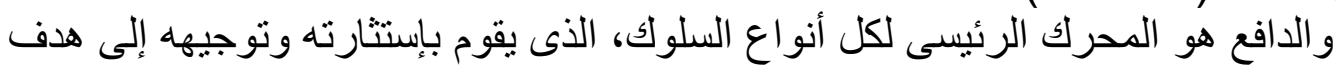

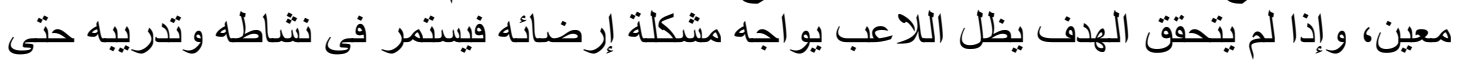

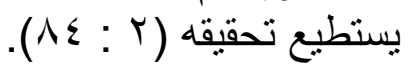

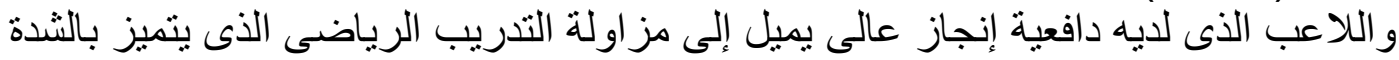

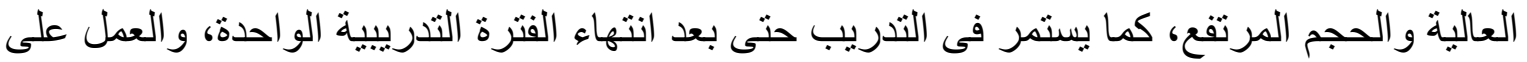

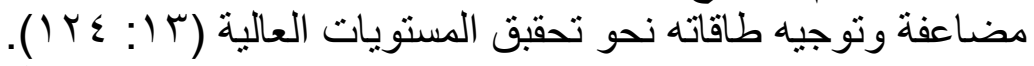

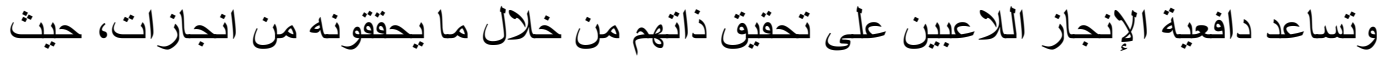
يتصفون بمستوى عال من فاعلية الذات و القدرة على ادر الك قدر اتهم واستطاعتهم و امتلاكهم القدر 
الكبير من الدافعية الداخلية و الثقة بالنفس و القدرة على مو اجهة خبر ات الفشل وبذل المزيد من الجهد

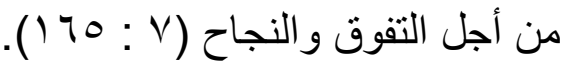

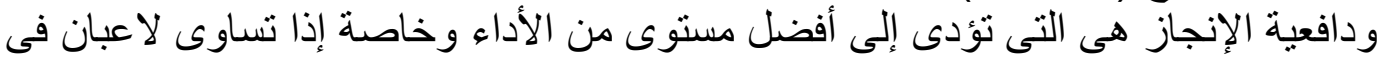
القدرة ولكنهما لم يتساويا فى دافعية الإنجاز فاللاعب ذا دافيل دافعية الإنجاز الأعلى يقدم الأداء الأفضل

وبذللك فإن دافعية الإنجاز هى العلاقة بين دو افع النجاح ودو افع تجنب الفنشل و التفاعل بينهما،

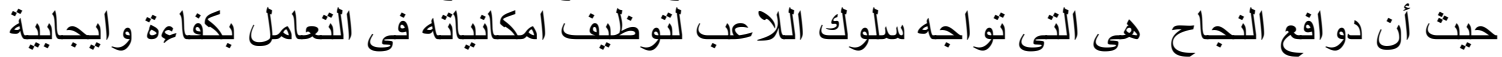

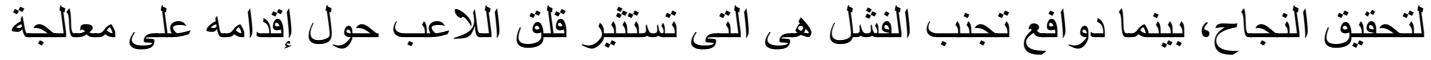

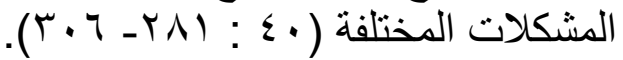
وتتثابه رياضة الجودو و الكار اتيه و التايكوندو في أنها من الأنشطة النز الية التى بعتمد الفوز

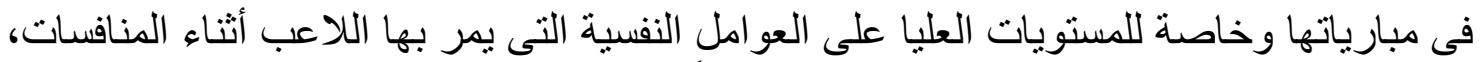

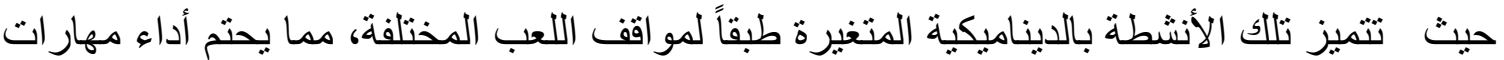

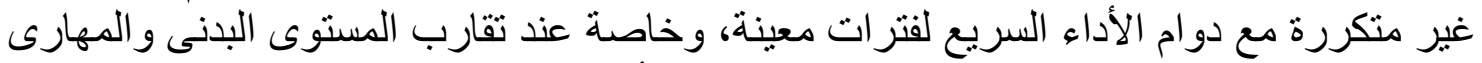

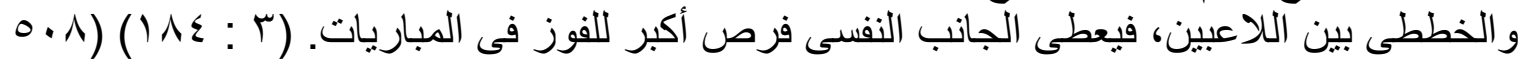
( $\{\tau)(\leqslant 0)(\leqslant \varepsilon)(r \leqslant$ :

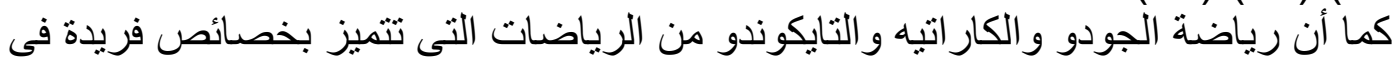

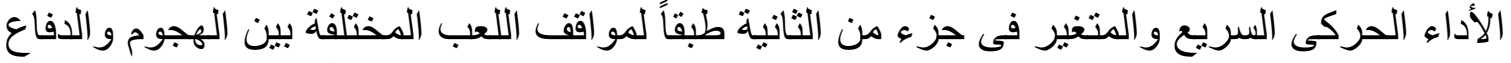

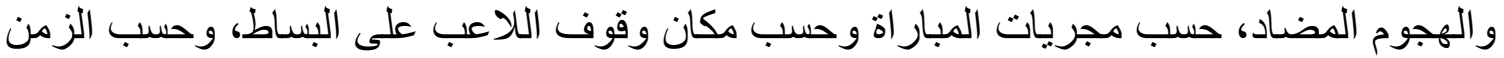

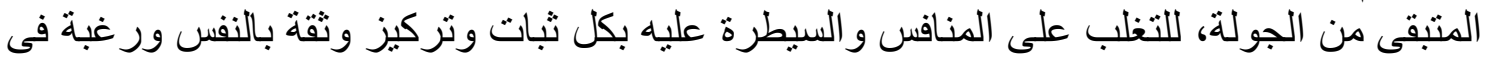

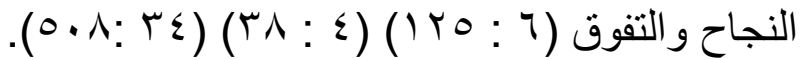

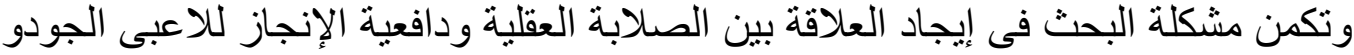

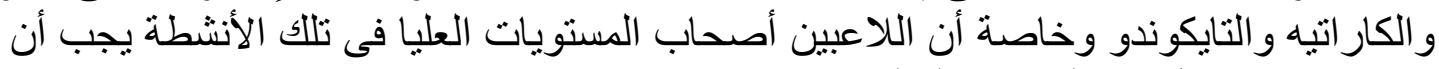

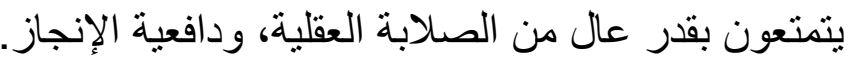

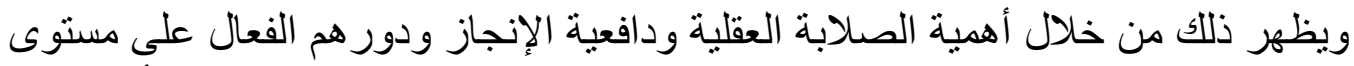

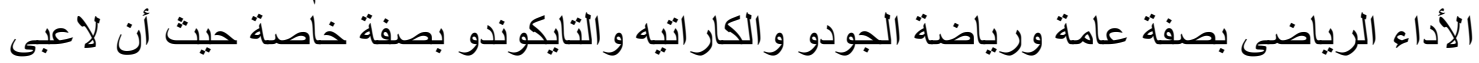

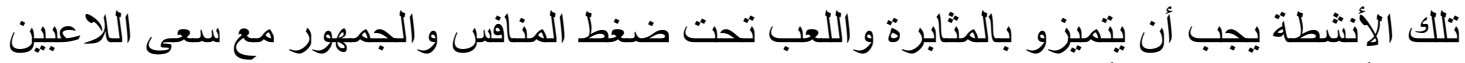

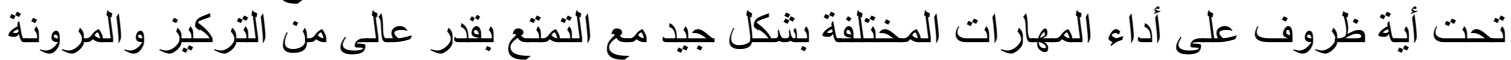

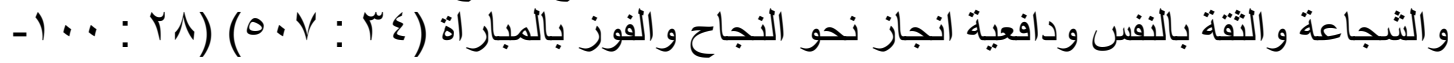

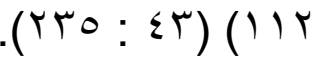

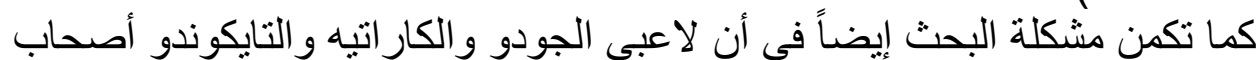

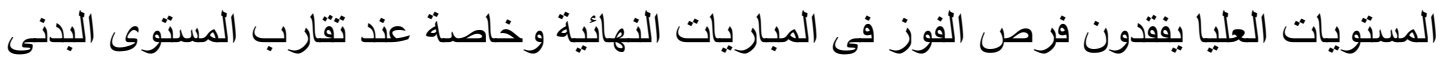

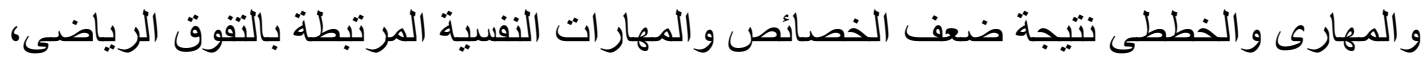

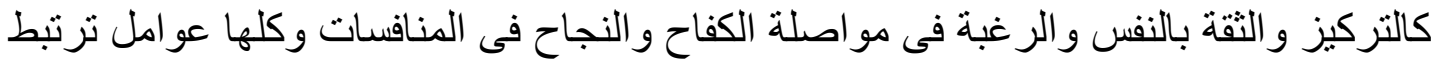

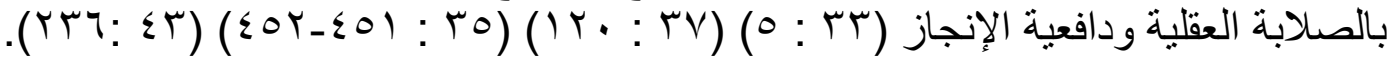
مما دعا الباحث إلى التعرف على التى العلاقة بين الصدابة العابة العقلية ودافعية الإنجاز للاعبى الجودو

و الكار اتيه و التايكوندو ودر اسلة الفروق بينهم.

يهذف البحث إلى تحديد العلاقة بين الصلابة العقلية ودافعية الإنجاز لبعض لاعبى أنثطة

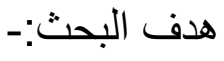

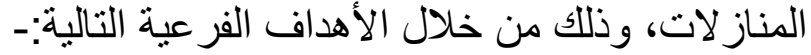

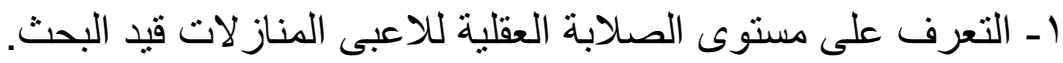

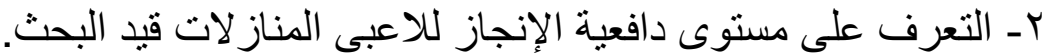

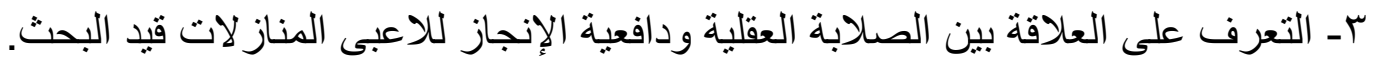
ــ التعرف على الفروق بين الصلابة العقلية ودافعية الإنجاز للاعبى المناز لاعلات لات قيد البحث. 


\section{تساؤلات البحث:-}

ا - ما مستوى الصالابة العقلية للاعبى المناز لات الات قيد البحث.

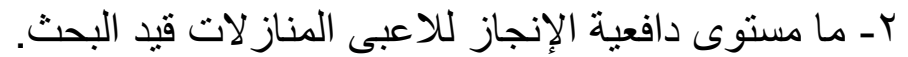

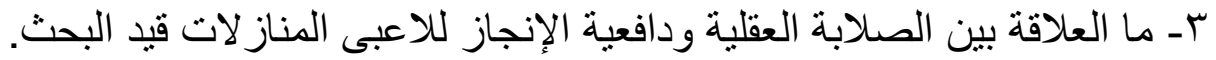

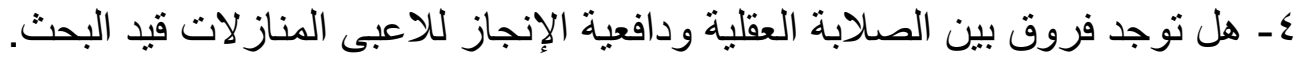

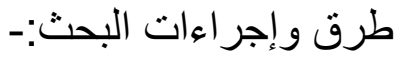
| - منهج البحث:-

تم استخدام المنهج الوصفى، حيث يعتبر ذللك مناسبا لتحقيق أهداف وتساؤلات البحث.

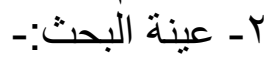
تم اختيار عينة البحث بالطريقة العدية من مجتمع البحث بأندية الجزيرة و الحوار و الناصرية

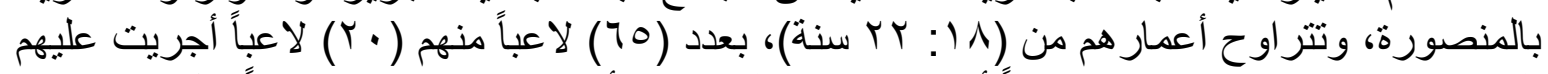

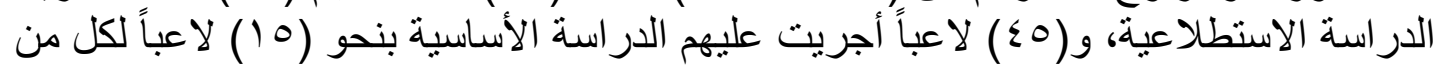

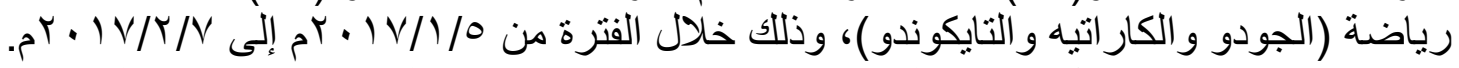

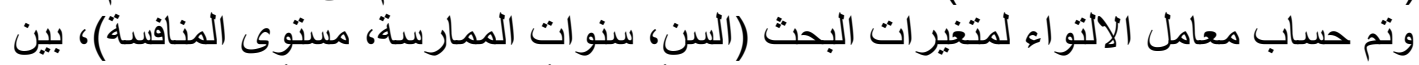

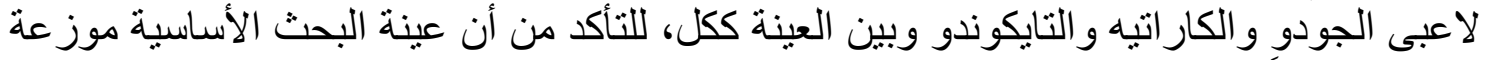

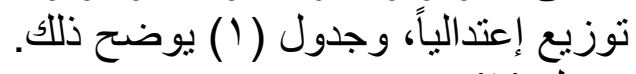

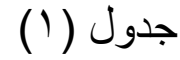
المتوسط الحسابى و الانحر اف المعيارى ومعامل الالتواء لعينة البحث الأساسية

\begin{tabular}{|c|c|c|c|c|c|}
\hline |الالتواء |اء |ل & الانحر اف & المتوسط & المناز لات & | المتغير ات & s \\
\hline$\cdot, r_{-}$ & $\cdot, \wedge \mu$ & $r \cdot, \leqslant V$ & الجودو (ن=0 إ) & \multirow{4}{*}{ 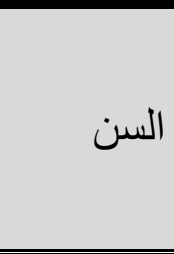 } & \multirow{4}{*}{1} \\
\hline$\cdot, \mathrm{r \Lambda}$ & $\cdot, \mathrm{VV}$ & $19, \wedge$. & الكار اتيه (ن=010) & & \\
\hline$\cdot, 1{ }_{-}$ & $\cdot, \wedge$. & $r \cdot, \cdot V$ & التايكوندو (ن=0 1 ) & & \\
\hline$\cdot, \cdot r$ & $\cdot$, ,Ar & $r \cdot, 11$ & العينة الأساسية (ن=0 §) & & \\
\hline$\cdot, 1 \mu_{-}$ & $\cdot, \wedge$. & $\Lambda, \cdot \vee$ & الجودو (ن=0 ا ) & \multirow{4}{*}{ سنوات الممارسة } & \multirow{4}{*}{ r } \\
\hline$\cdot, r_{-}$ & $1, r \mu$ & $\mathrm{V}, \mathrm{TV}$ & الكار اتيه (ن=0 إ) & & \\
\hline$\cdot, \leqslant 9-$ & $1,+1$ & $\vee, \wedge$. & التايكوندو (ن=0 ا ) & & \\
\hline$\cdot, \leqslant \Lambda_{-}$ & $1, \cdot Y$ & $\vee, \wedge \varepsilon$ & العينة الأساسية (ن=0 ؟) & & \\
\hline 1,11 & $\cdot, \leqslant 7$ & $1, Y V$ & الجودو (ن=0 إ) & \multirow{4}{*}{ المنافتوى } & \multirow{4}{*}{ r } \\
\hline$\cdot, \leq 7-$ &., 01 & $1,7$. & الكار اتيه (ن=0 إ) & & \\
\hline$\cdot, \leqslant \nearrow_{-}$ &., 01 & 1,7 . & التايكوندو (ن=0 ا م) & & \\
\hline$\cdot, .0_{-}$ &., 01 & $1, \leqslant 9$ & العينة الأساسية (ن=0 §) & & \\
\hline
\end{tabular}

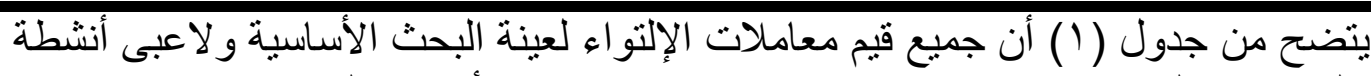

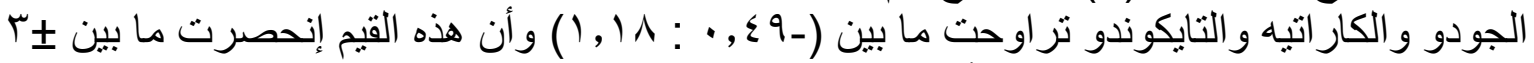

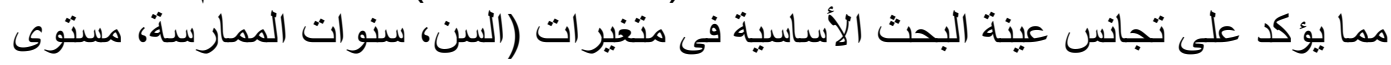
المنافسة).

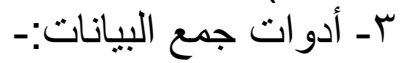
مقياس الصصابة العقلية:-

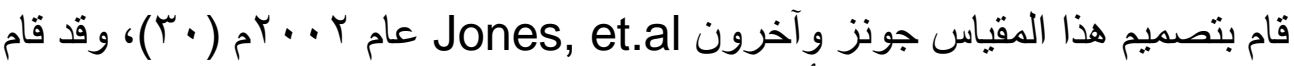

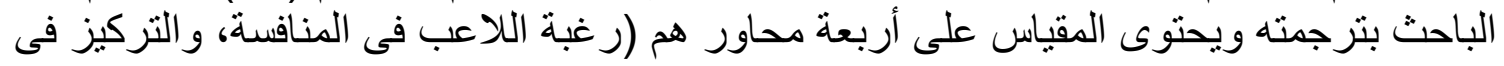

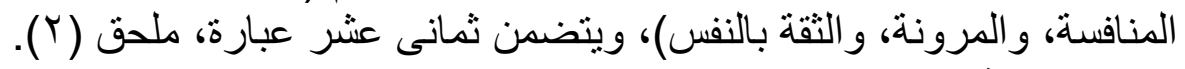
مقياس دافعية الإنجاز :- 


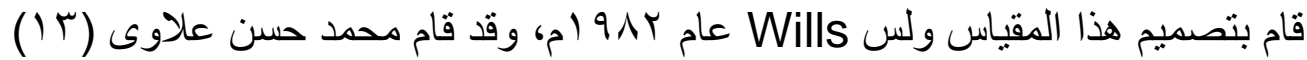
بتعريبه ويحتوى الدقياس على محورين هم (دافع انجاز النجاح، ودافع تجنب الفنشل) ويتضن

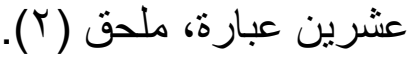

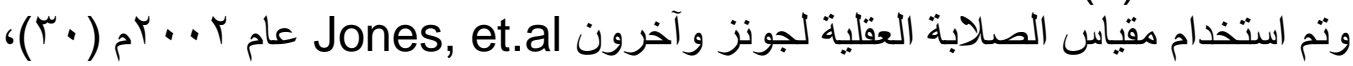

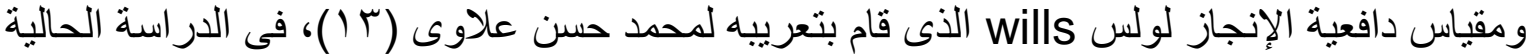

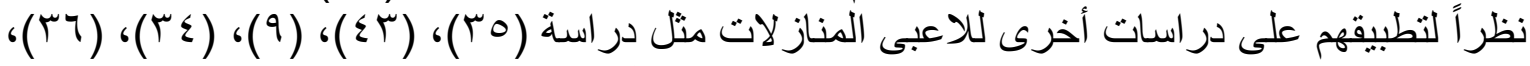

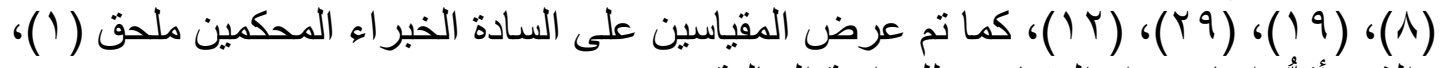

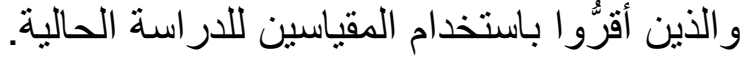

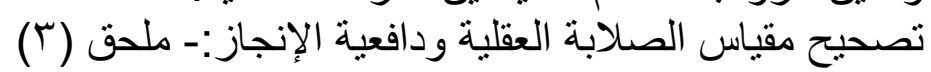
المعاملات العلمية للمقياسين:-

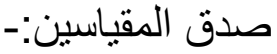

تم استخدام صدق المحكمين للتأكد من الصدق الظاهرى الذى يشير إلى أن الأداة تقيس بشكل

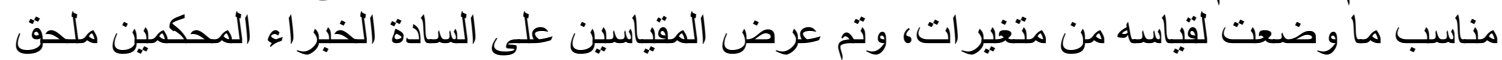

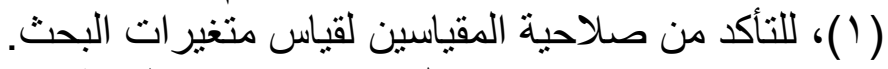

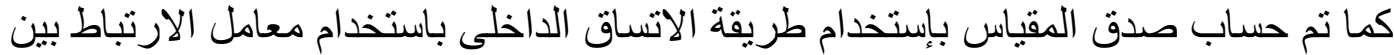

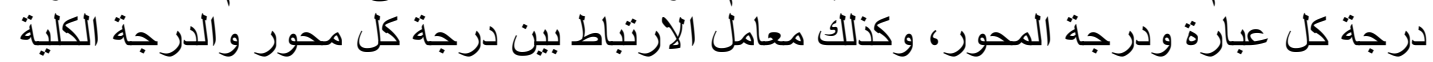

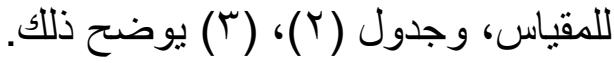

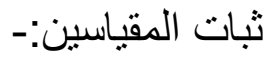

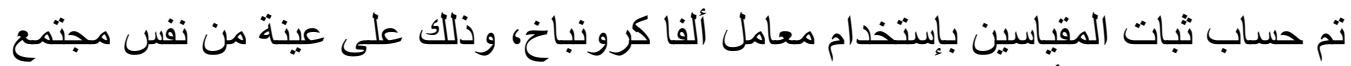

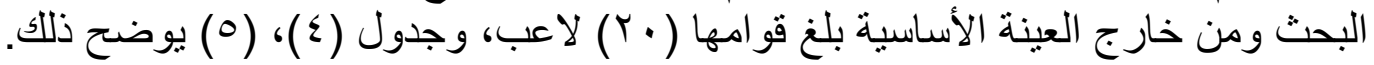


جدول (r)

معامل الارتباط بين العبار ات و المحور وبين المحور و الدرجة الكلية لمقياس الصلابة العقلية

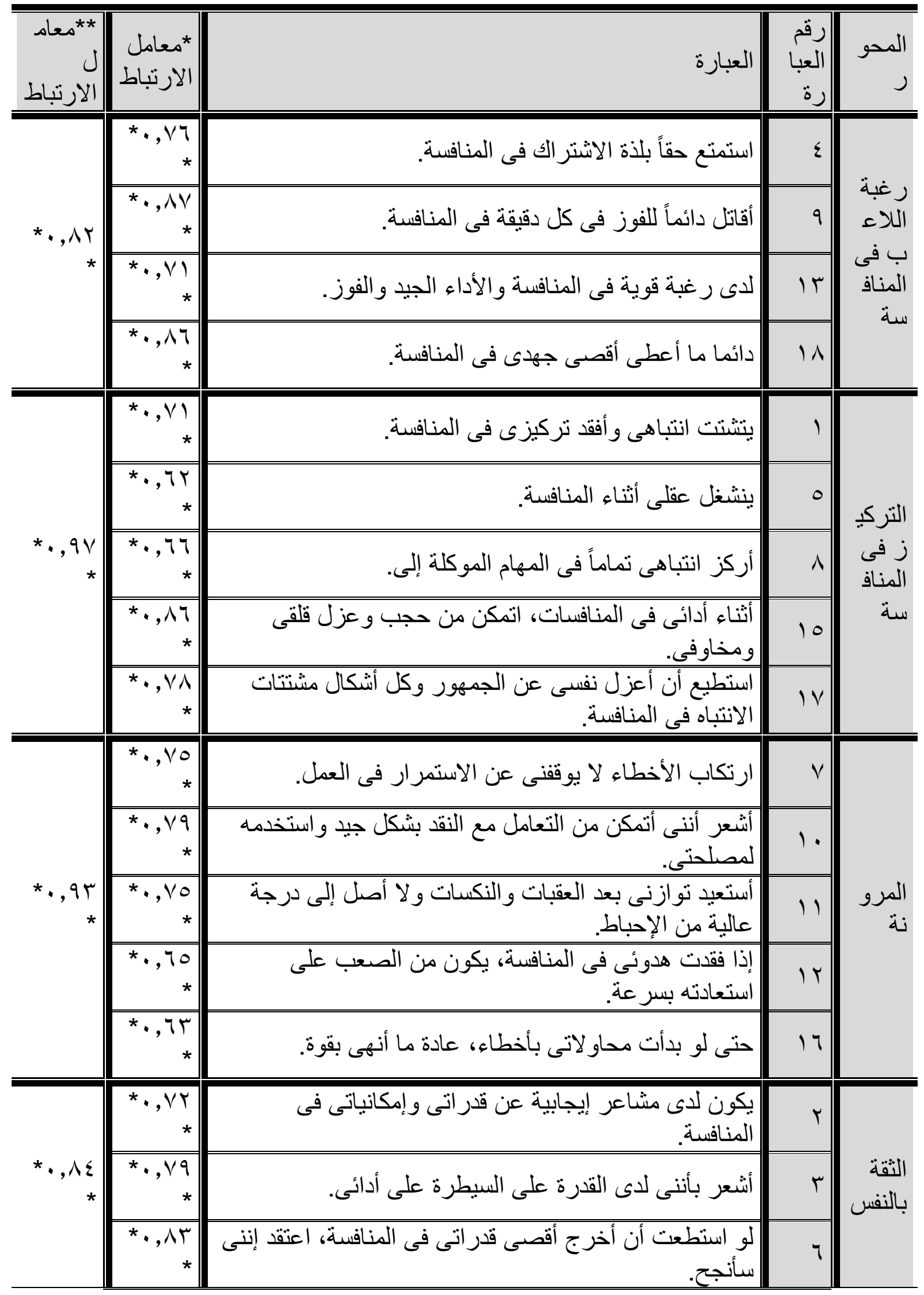




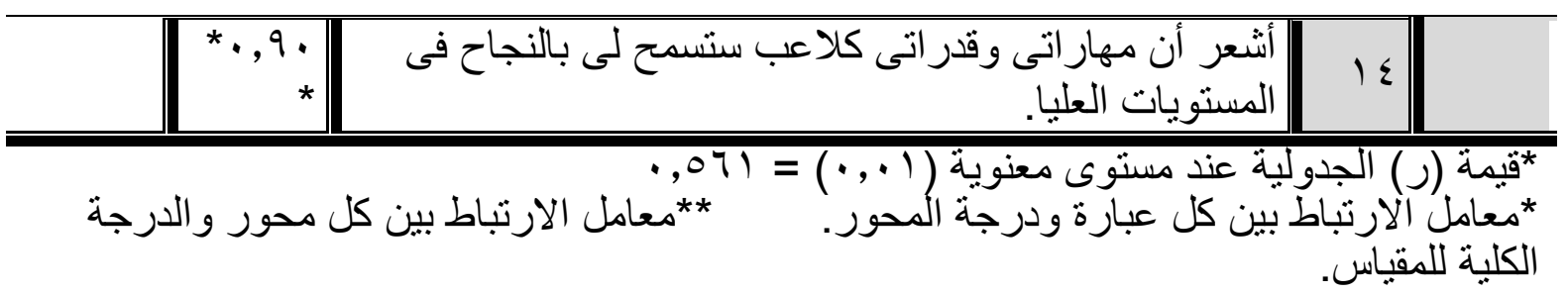


جدول (r)

معامل الارثباط بين العبار ات و الدحور وبين الدحور و الدرجة الكلية للقياس دافعية الإنجاز

\begin{tabular}{|c|c|c|c|c|}
\hline 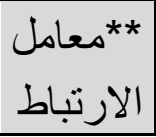 & الارنباط & العبارة & 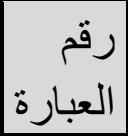 & حور \\
\hline \multirow{10}{*}{$*^{* *}, \vee \wedge$} & ${ }^{* *},, \vee \vee \downarrow$ & يعتبنى اللاعب الذى يتدرب لساعات إضافية لتحسين & $r$ & \multirow{10}{*}{ النجاز } \\
\hline & $* *$, ov & الامتياز فى الرياضة لا يعد من أهدافى الأساسية. & $\varepsilon$ & \\
\hline & $\left.{ }^{* *},, \vee \backslash\right)$ & أستها مهمعة صتحملة أية مهمة يرى فيها بعض اللاعبين الآخرين & 7 & \\
\hline & $* *, 00$ & الحظ يؤدى إلى الفوز بدرجة اكبر من بذل الجهد. & $\Lambda$ & \\
\hline & $* *, 7$. & في رياضتى استعداد للتنريب طو ال العام بدون انقطاع لكى انجح & 1. & \\
\hline & $* *, 07$ & الفوز فى المنافسة يمنحنى درجة كبيرة من الرضا. & $1 Y$ & \\
\hline & **,,$\pi$ & أفضافل أن أستريح فى التدريب فى فترة ما بعد الانتهاء من & $1 \varepsilon$ & \\
\hline & $* *, \vee$ & لدى رغبة عالية جداً لكى أكون ناجحاً فى رياضتى. & 17 & \\
\hline & $* * ., 79$ & أحاول بكل جهدى أن أكون أفضل لاعب. & 11 & \\
\hline & $* *,, T \leqslant$ & هدفى هو أن أكون مميزاً في رياضتى. & $r \cdot$ & \\
\hline \multirow{10}{*}{$* *_{,}, \wedge 9$} & $* *, 09$ & أجد صعوبة فى محاولة النوم عقب هزيمتى فى أى منافسه. & 1 & \multirow{10}{*}{ تلجنب } \\
\hline & $* *, 77$ & 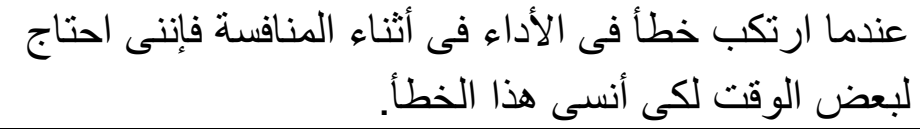 & $r$ & \\
\hline & $* *, 0 \wedge$ & أحس غالباً بالخوف قبل اشتر اكى فى المنافسة مباشرة & 0 & \\
\hline & $* *, 0 \mathrm{~V}$ & آخشى الهزيمة فى المنافسة. & $\mathrm{V}$ & \\
\hline & $* *, 00$ & لعدة أيام. & 9 & \\
\hline & $* *, 01$ & لا أجد صعوبة فى النوم ليلة اثتر اكى فى منافسة. & 11 & \\
\hline & $* *, 71$ & اشعر بالتوتر قبل المنافسة الرياضية. & $1 \pi$ & \\
\hline & **,, $7 \leq$ & المنافسة. ارتكب خطأ فى الأداء فان ذللك ير هقنى طو ال فترة & 10 & \\
\hline & $* * . V 4$ & 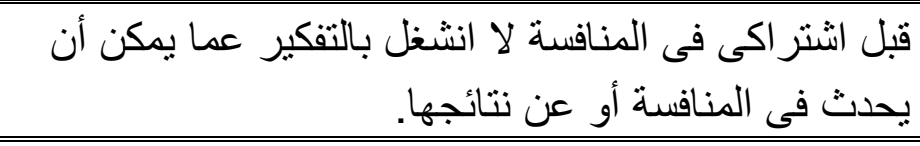 & IV & \\
\hline & $* *, .09$ & أحاول بكل جهدى أن أكون هادئاً فى اللحظات التى تسبق & 19 & \\
\hline
\end{tabular}


|معامل الارتباط بين كل محور و الدرجة

"معامل الارتباط بين كل عبارة ودرجة المحور.

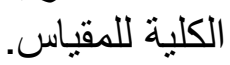

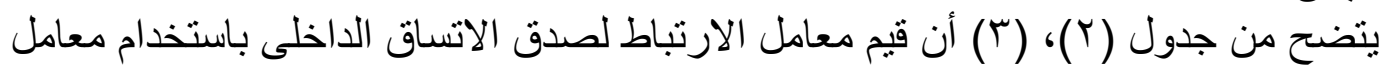

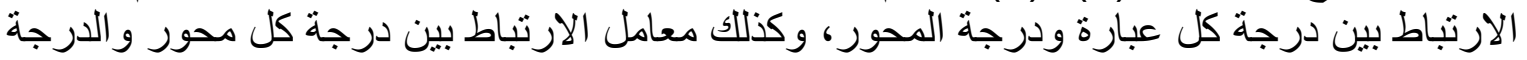

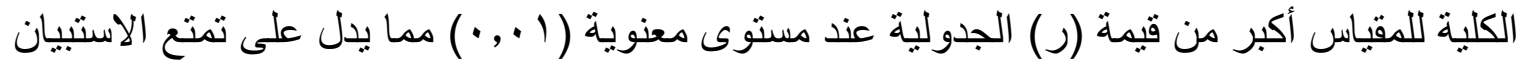

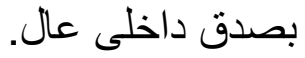

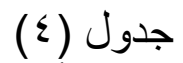

معامل ألفا كرونباخ لثبات محاور مقياس الصلابة العقلية

r. $=\dot{~}$

\begin{tabular}{|c|c|c|}
\hline ألفا كرونباخ & |المحور & ? \\
\hline$\cdot, \mathrm{\vee} \wedge$ & |رغبة اللاعب فى التنافس. & 1 \\
\hline$\cdot, \mathrm{VT}$ & | التركيز. & r \\
\hline$\cdot, 1 / 4$ & | المرونة. & $r$ \\
\hline$\cdot, \Lambda$. & |الثقة بالنفس. & $\varepsilon$ \\
\hline., 94 & |إجمالى المقياس. & 0 \\
\hline
\end{tabular}

معامل ألفا كرونباخ لثبات محاور مقياس دافعية الإنجاز

$r \cdot=\dot{T}$

\begin{tabular}{|c|c|c|}
\hline معامل الارتباط & |الدحور | & \\
\hline$\cdot, \Lambda \mu$ & دافع إنجاز النجاح. & 1 \\
\hline$\cdot, \wedge 1$ & دافع تجنب الفشل. & r \\
\hline$\cdot, \wedge 0$ & || إجمالى الدقياس. & $r$ \\
\hline
\end{tabular}

يتضح من جذول ( ع)، (0) معاملات ثبات كل من مقياس الصلابة العقلية ودافعية الإنجاز

حيث تقترب من الواحد الصحيح مما يدل على ثبات عالى للى للمقياسين. 


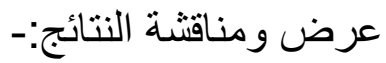

1 ـ التعرف على مستوى الصلابة العقلية للاعبى المناز لات قبد البحث:-

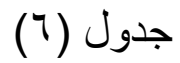

$\varepsilon 0=\dot{0}$

التكر ار و النسبة المئوية وكا؟ لمقياس الصلابة العقلية

\begin{tabular}{|c|c|c|c|c|c|c|c|c|c|c|c|c|c|c|c|}
\hline \multirow{3}{*}{ |الترتيب } & \multirow{3}{*}{ الدتوسطة } & \multirow{3}{*}{ اللبند } & \multirow{3}{*}{ المرجح } & \multicolumn{10}{|c|}{ درجة الاستجابة } & \multirow{3}{*}{${ }^{*}$} & \\
\hline & & & & \multicolumn{2}{|c|}{ أو افق بشدة } & \multicolumn{2}{|c|}{ أو افق } & \multicolumn{2}{|c|}{ محايد } & \multicolumn{2}{|c|}{ لا أو افق } & \multicolumn{2}{|c|}{ لا أو افق } & & \\
\hline & & & & $\%$ & عدد & $\%$ & عدد & $\%$ & عدد & $\%$ & عدد & $\%$ & عدد & & \\
\hline 1 & $\cdot, 9 \varepsilon$ & \multirow{4}{*}{$Y \wedge, \wedge T$} & $1 \varepsilon, 1 \%$ & $V \vee, \Lambda$ & ro & 10,7 & V & $7, V$ & $r$ & . & . & . & . & $\xi$ & \\
\hline$Y$ &., $9 \leqslant$ & & $1 \varepsilon, 1 \pi$ & $v 1,1$ & TY & rA, q & 11 & . & . & . & . & . & . & 9 & \\
\hline$r$ & $\cdot, 94$ & & IT,AV & $77, V$ & $r$. & r, & $1 \varepsilon$ & . & . & Y,Y & 1 & . & . & 11 & \\
\hline$\varepsilon$ & $\cdot, 9$. & & $1 \Gamma, \varepsilon \Gamma$ & $7 \cdot, \cdot$ & TV & $\overline{r, 1}$ & $1 \xi$ & $\overline{7, V}$ & $\bar{r}$ & $\overline{Y, Y}$ & 1 & - & $\cdot$ & 11 & \\
\hline$\varepsilon$ & $\cdot, \vee \wedge$ & \multirow{5}{*}{ IT,KT } & $11, V \mu$ & . & . & $\Lambda, 9$ & $\varepsilon$ & 10,7 & V & 01,1 & $r \mu$ & $r \leqslant, \varepsilon$ & 11 & 1 & \\
\hline 0 & $\cdot, \sqrt{ } 7$ & & $11, \leqslant V$ & $Y, Y$ & 1 & $\varepsilon, \xi$ & r & Y & 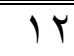 & $\varepsilon Y, Y$ & 19 & $r \varepsilon, \varepsilon$ & 11 & 0 & \\
\hline 1 & $\cdot, \wedge \wedge$ & & $I T, Y V$ & $0 Y, r$ & $T \leq$ & $T 0,7$ & 17 & 11,1 & 0 & . & . & ${ }^{\circ}$ & $\cdot$ & $\Lambda$ & \\
\hline$\Gamma$ & $\cdot, \wedge 1$ & & $\mid I Y, I T$ & $\overline{Y Y, Y}$ & 1. & $7 \cdot, \cdot$ & $T V$ & $I V, \Lambda$ & $\bar{\Lambda}$ & . & . & . & . & 10 & \\
\hline$Y$ & $\cdot, \wedge \vee$ & & $1 \%, \ldots$ & $\varepsilon 7, V$ & YI & $\varepsilon \cdot, \cdot$ & 11 & $1 r, r$ & 7 & . & . & . & $\cdot$ & IV & \\
\hline$\varepsilon$ & $\cdot, \wedge \Sigma$ & \multirow{5}{*}{$1 Y, 07$} & Ir,T. & 01,1 & $\overline{r r}$ & $r q, V$ & $T H$ & 10,7 & $\bar{v}$ & $\xi, \varepsilon$ & $\bar{r}$ & $\overline{r, Y}$ & 1 & $\bar{v}$ & 5 \\
\hline 1 & $\cdot, \wedge \wedge$ & & $I T, r$. & $\varepsilon 7, V$ & YI & $\leqslant 7, V$ & YI & $7, \mathrm{~V}$ & $r$ & . & . & . & $\cdot$ & 1. & \\
\hline$r$ & $\cdot, \wedge 7$ & & $1 Y, 94$ & $\sum \tau, V$ & YI & $\varepsilon \cdot, \cdot$ & 11 & 11,1 & 0 & T,Y & 1 & . & . & 11 & \\
\hline 0 & $\cdot, V T$ & & $11, \varepsilon$. & $\overline{Y, Y}$ & $T$ & . & . & $\overline{\mu r, r}$ & 10 & $\varepsilon \varepsilon, \xi$ & $r$. & $r_{\cdot, \cdot}$ & 9 & IT & \\
\hline$\Gamma$ & $\cdot, \wedge \varepsilon$ & & IT,TV & Tr,T & 10 & 00,7 & ro & 11,1 & 0 & . & . & . & . & 17 & \\
\hline$\varepsilon$ & $\cdot, 9$ & \multirow{4}{*}{$I T, T V$} & $1 T, \leqslant V$ & 00,7 & ro & $r \vee, \Lambda$ & IV & $7, \mathrm{~V}$ & $r$ & $\cdot$ & . & 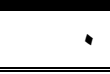 & 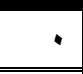 & Y & \\
\hline$T$ &., 91 & & $1 T, T V$ & 00,7 & TO & «ई, & $r$. & . & . & . & . & . & . & $\bar{r}$ & \\
\hline$r$ & $\cdot, 91$ & & $1 \pi, \pi$. & $\overline{V \Psi, \Gamma}$ & Tr & 10,7 & V & $\overline{Y, Y}$ & 1 & $\Lambda, 9$ & $\xi$ & . & . & $\overline{7}$ & \\
\hline 1 & $\cdot 94$ & & $1 \%, 9 \pi$ & 71,9 & Tा & YY,V & $1 Y$ & $\varepsilon, \varepsilon$ & $\bar{r}$ & - & - & . & $\bullet$ & $1 \varepsilon$ & \\
\hline
\end{tabular}

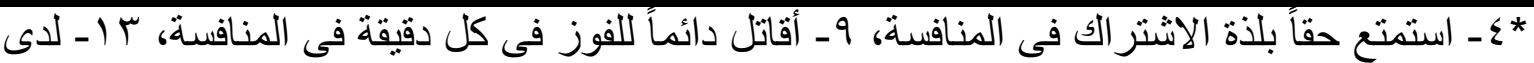

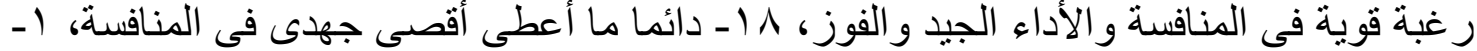

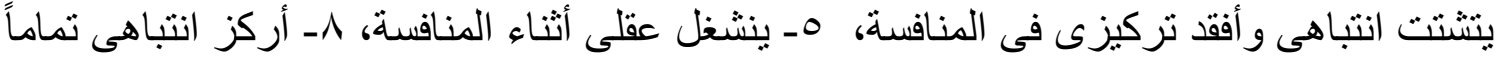

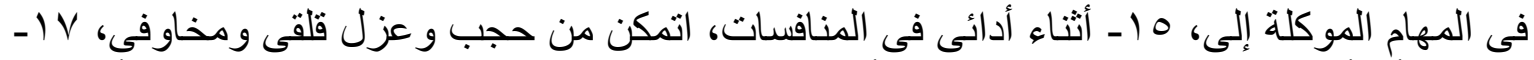

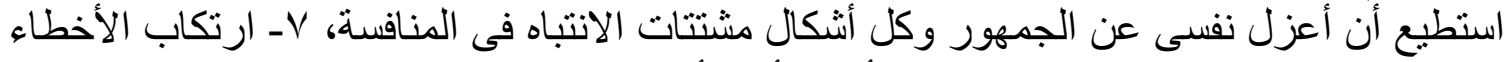

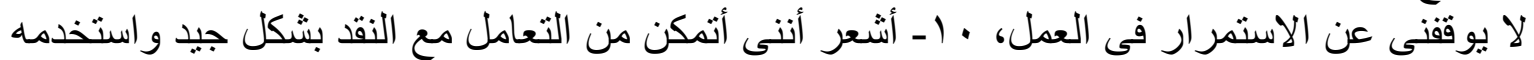

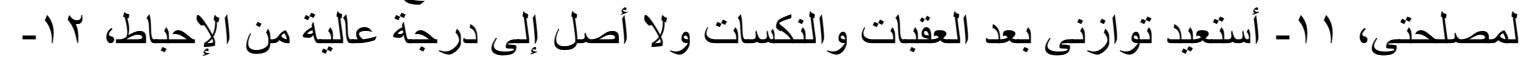

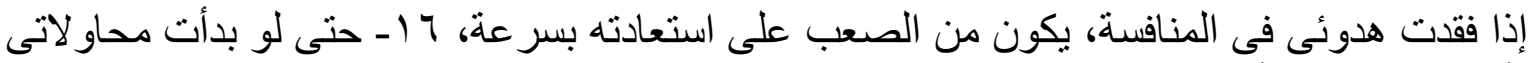

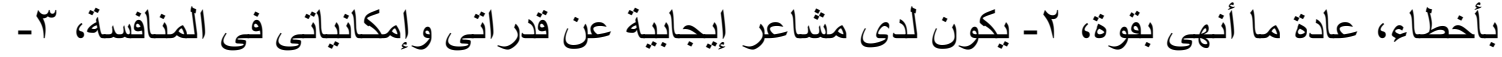

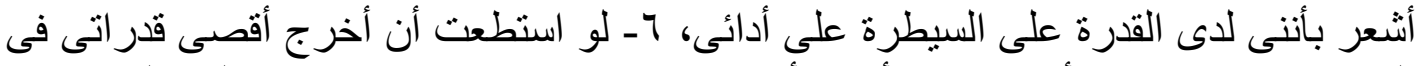

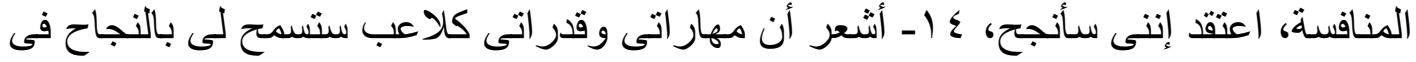


يتضح من جدول (T)، بالنسبة لعبار ات المحور الأول (رغبة اللاعب في المنافسة) لمقياس

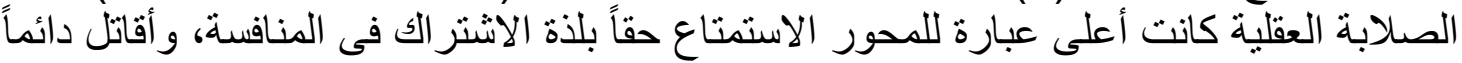

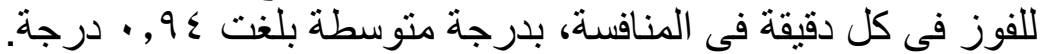

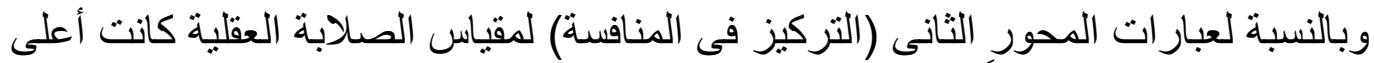

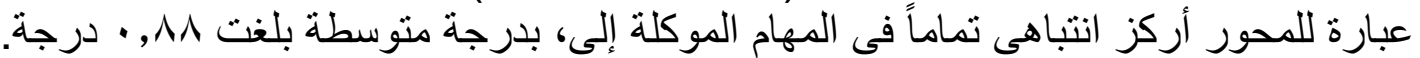

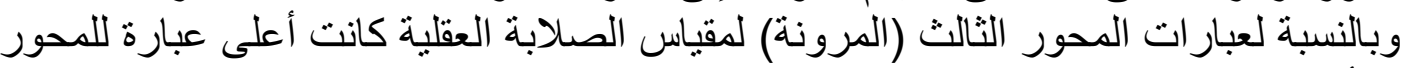

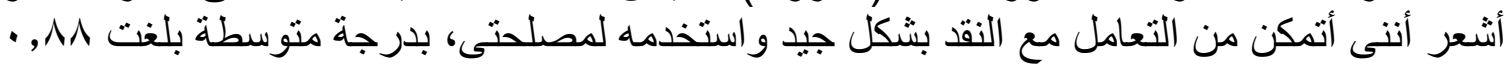

وبالنسبة لعبار ات المحور الر ابع (الثقة بالنفس) لمقياس الصلابة العقلية كانت أعلى عبارة للمحور أشعر أن مهار اتى وقدر اتى كلاعب ستسمح لى بالنجاح فى المستويات العليا، بدرجة متوسطة

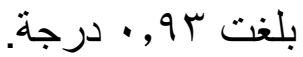
كما أثنتت النتائج التفصيلية وجود فروق دالة إحصائياً عند مستوى معنوية (0 . , • ) لجميع قيم كا' لجميع محاور المقياس.

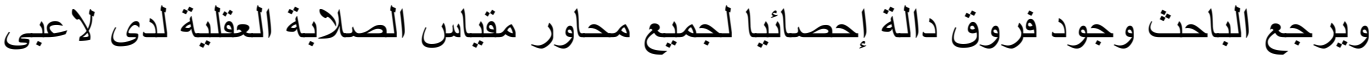

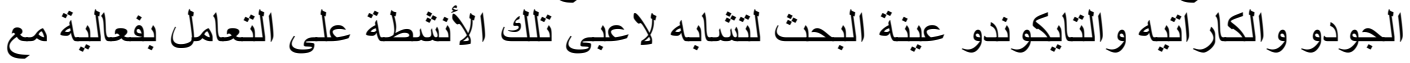

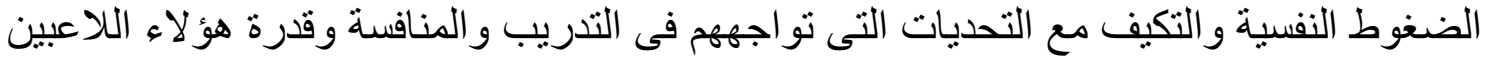

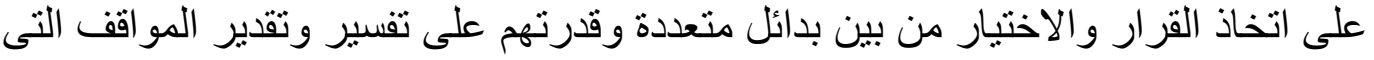

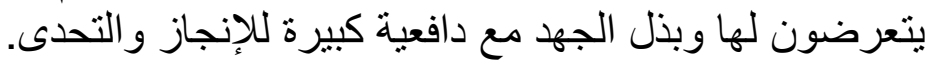

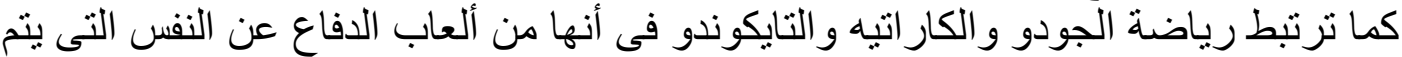

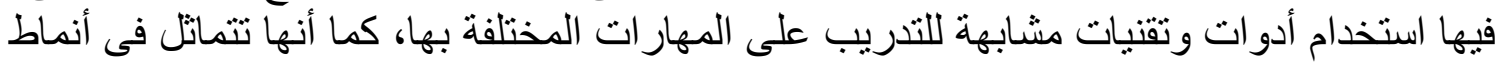

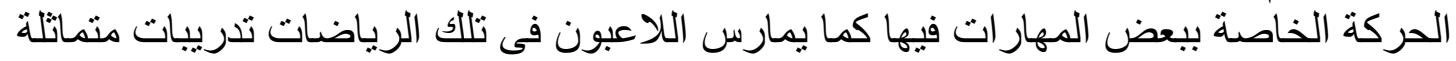

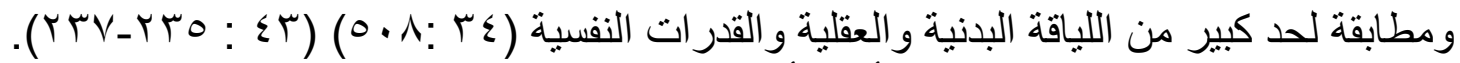

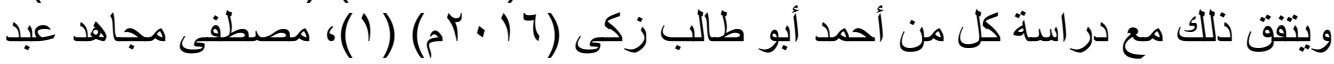

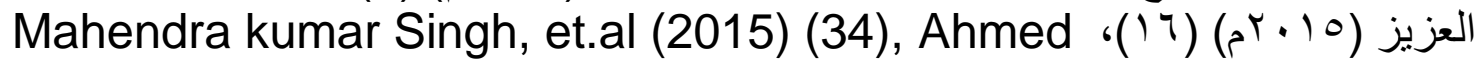
Aly, Ahmed El Emiri (2014) (19), Ramesh Chand Yadav (2014) (41),

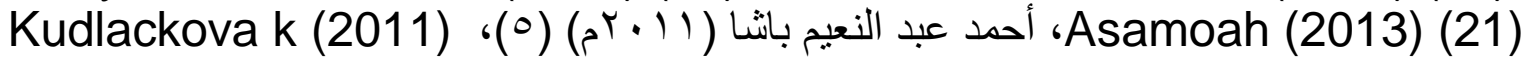

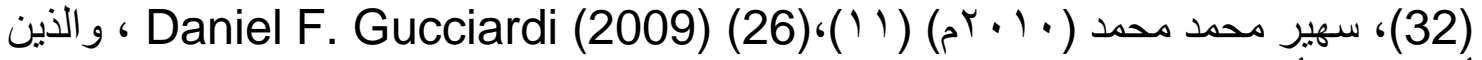
أكدوا على أن اللاعبين الذين يمتلكون قدر عالى من الصلابة العقلية يستطيعون مواجهة ضغوط

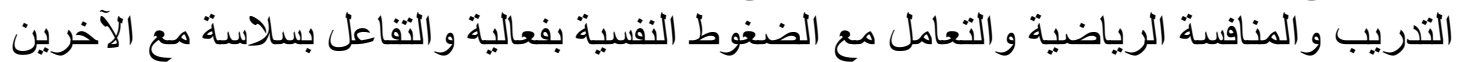

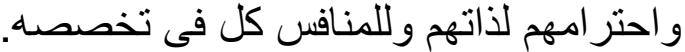
وبذلك تمت الأجابة على التساؤل الأول والفي كلى الذى ينص على ما مستوى الصلابة العقلية للاعبى

$$
\text { بـ المناز لات قيد البحث: على مستوى دافعية الإنجاز للاعبى المناز لات قيد البحث:- }
$$

جدول (V)

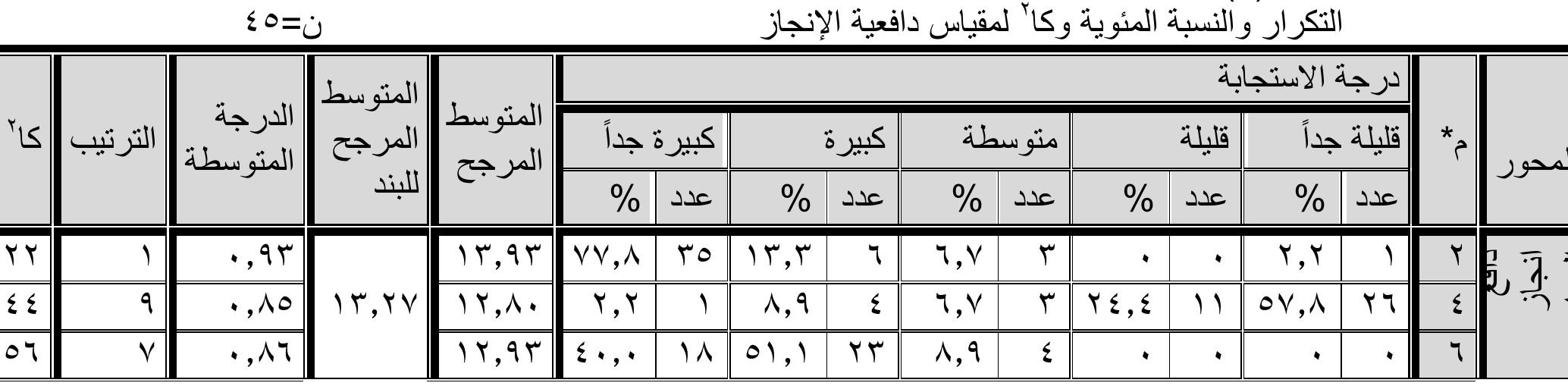




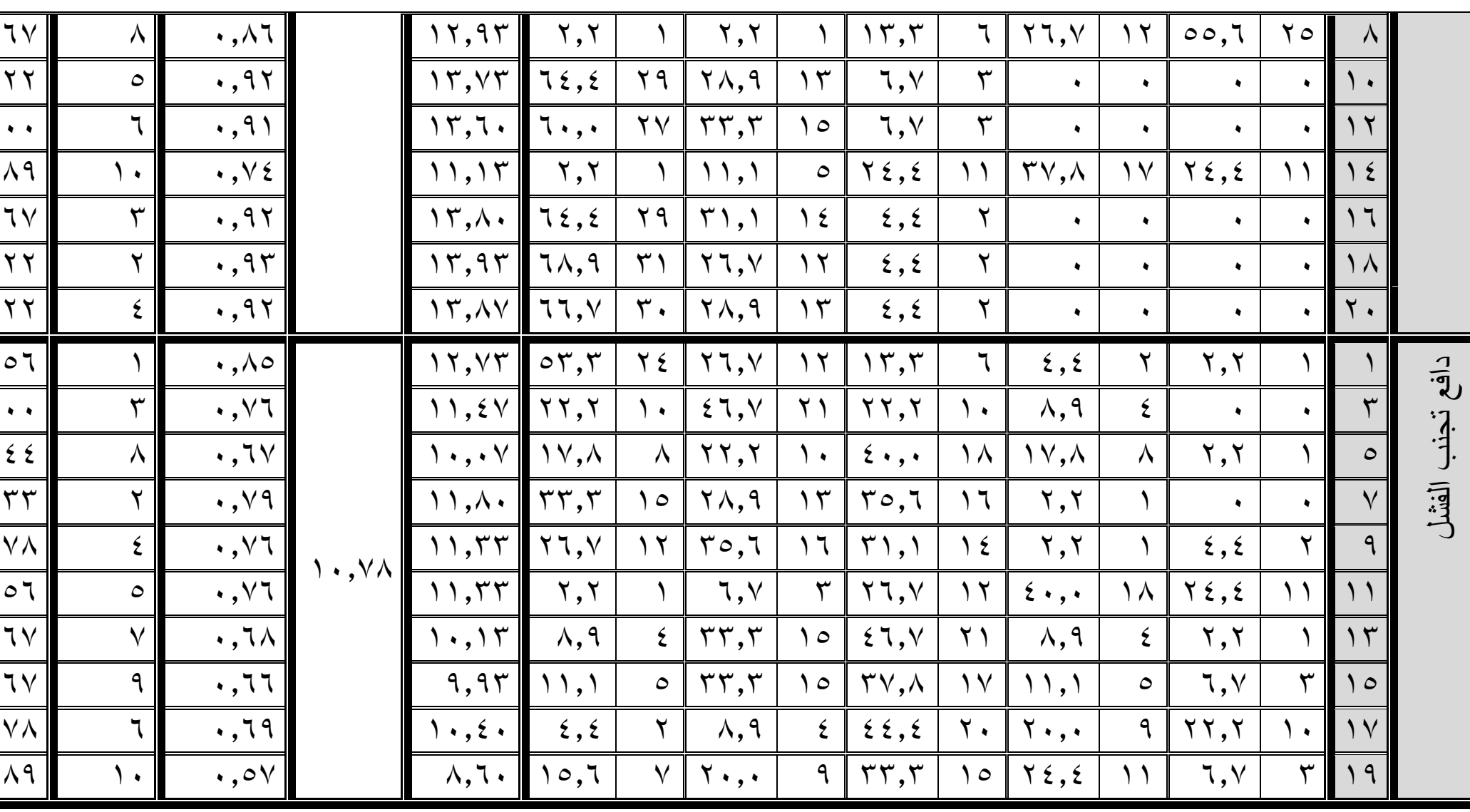

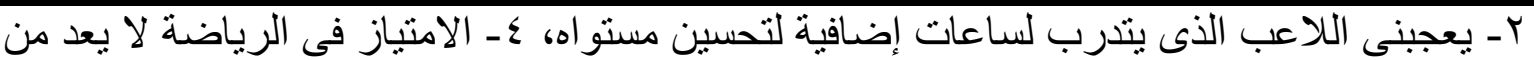

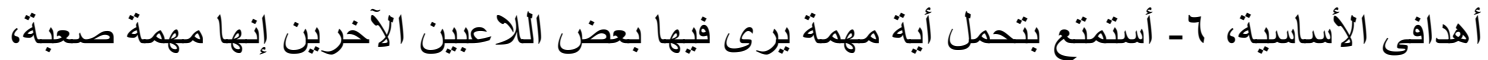

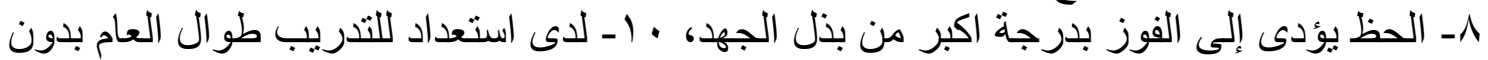

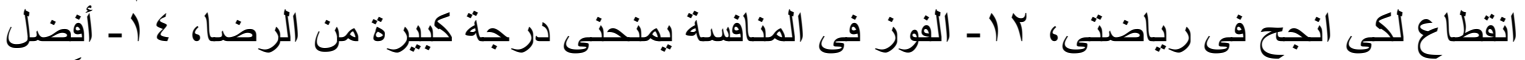

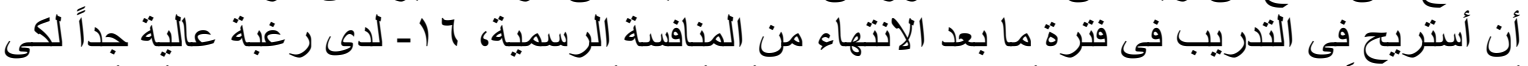

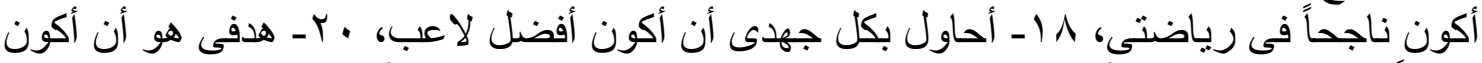

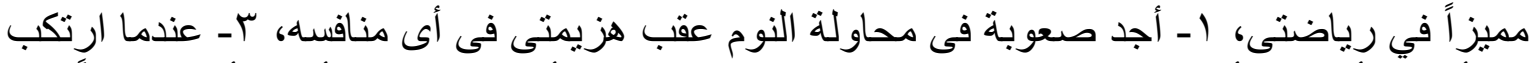

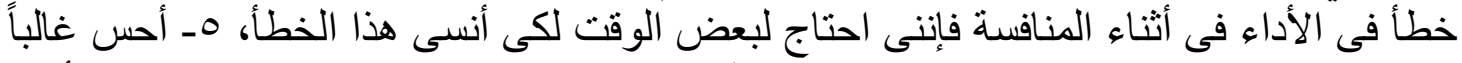

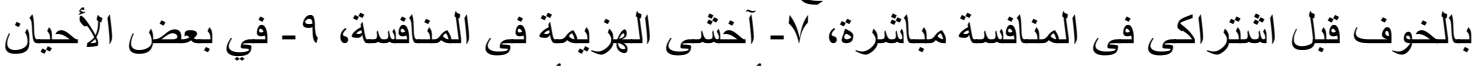

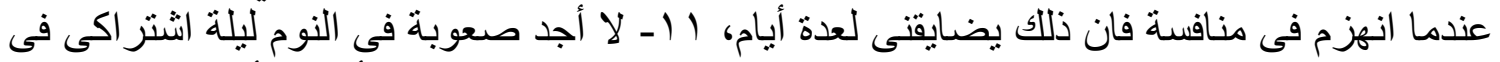

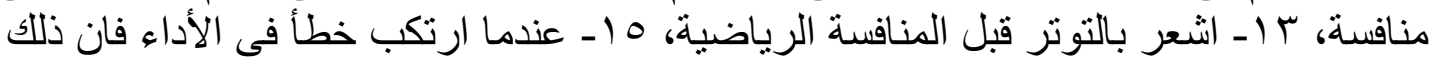

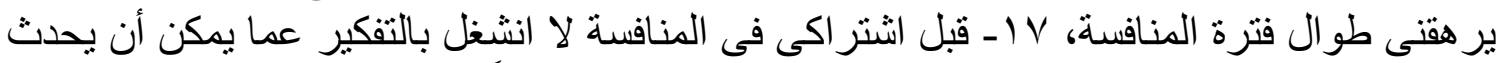

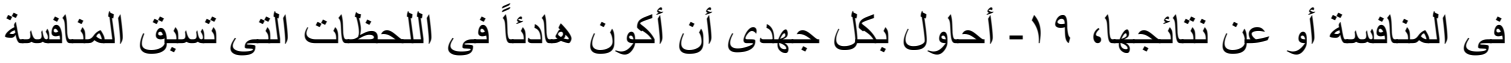
مباشرة. يتضح من جدول (V)، بالنسبة لعبار ات المحور الأول (انجاز النجاح) لمقياس دافعية الإنجاز

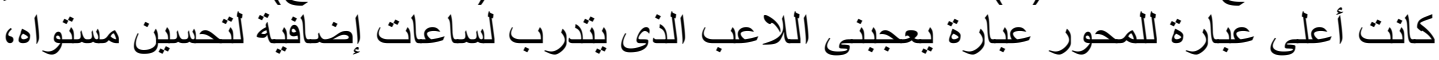

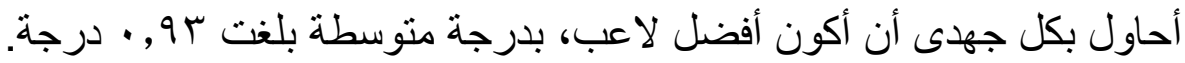

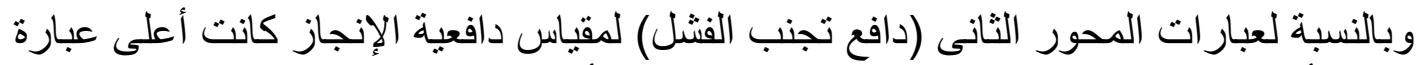

للمحور عبارة أجد صعوبة فى محاولة النوم عقب هزيمتى فى أى منافسه، بدرجة منوسطة بلغت دالت الانس 10 • • درجة. كما أثتتت النتائج التفصيلية وجود فروق دالة إحصائياً عند مستوى معنوية (0 • , • ) لجميع قيم كا` لجميع محاور المقياس. 


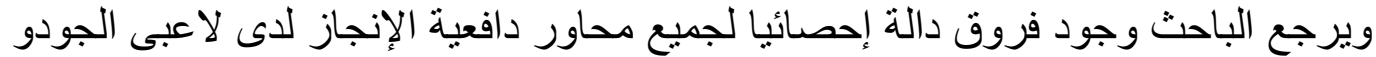

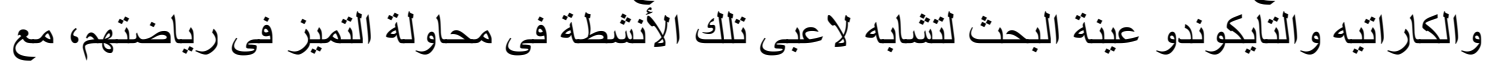
بذل المزيد من الجهد فى التدريب و المنافسة لتحقيق الامتياز و التفوق من أجل السيطرة لإنى على التحديات

وتعتمد دافعية الإنجاز على الرغبة فى التفوق و على طبيعة المنافسة و الأهنمام بها من أجل الجل الامنياز و التفوق، و الميل إلى التعلم بصورة أسرع، و الميل كذلك إلى إلى المو اقف الته التى بستطيع التحكم

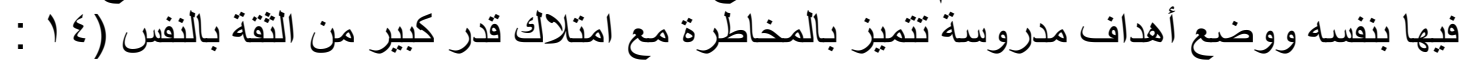
. ( ) $1 \leqslant 6$ ( )

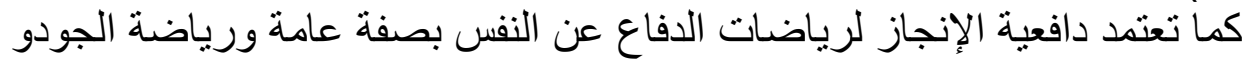

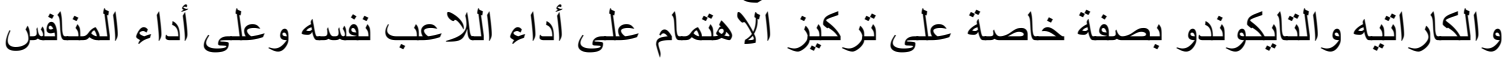

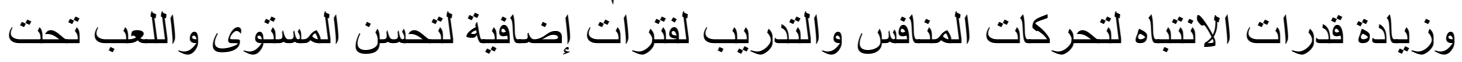
ضغط سواء من المنافس أو الجمهور أو أية أمور أخرى تتعلق بالمباه التبارة مع محاولة تحفيز التلاعبين

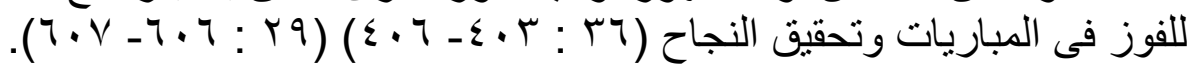

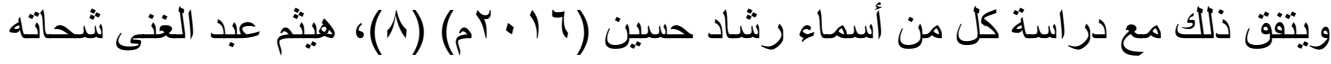

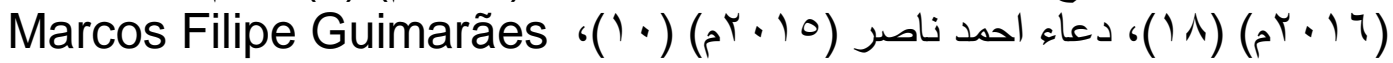
Pinheiro, et. al (2015) (36), Phairembam Jiteshwor (3013) (39), Javier

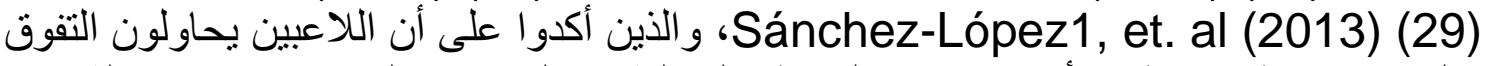

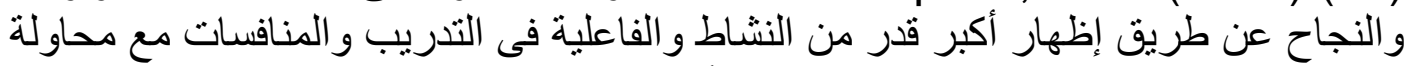

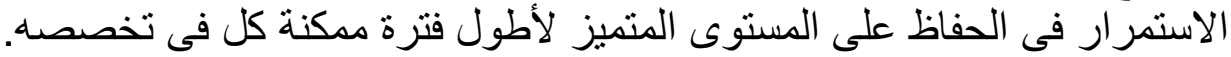

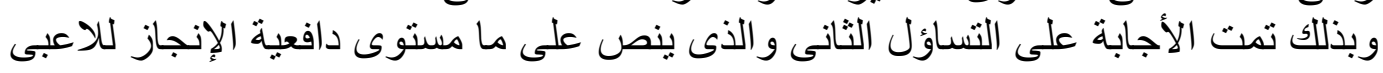


rـ التعرف على العلاقة بين الصلابة العقلية ودافعية الإنجاز للاعبى المناز لات قبد البحث:-

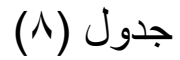

معامل الارتباط بين مقياس الصلابة العقلية ومقياس دافعية الإنجاز لدى لاعبى المناز لات

\begin{tabular}{|c|c|c|c|c|}
\hline 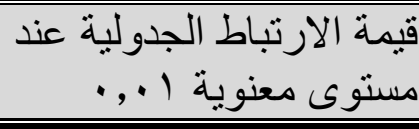 & العدد & الدستوى & 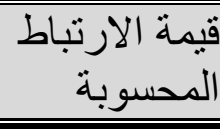 & المناز لات \\
\hline$\cdot, 7 \leqslant 1$ & 10 & $\cdot, \cdots 1$ & $* *,, V V$ & الجودو (ن==10) \\
\hline$\cdot, 7 \leqslant 1$ & 10 & $\cdot, \ldots$ & **.,人 & الكار اتيه (ن=0 1 \\
\hline., $7 \leqslant 1$ & 10 &,$+ \cdots$ & $* * \cdot, 19$ & التايكوندو (ن=010) \\
\hline.,$\Gamma \wedge 1$ & $\sum 0$ & $\cdot, \cdots$ & $* *,, 11$ & إجمالى المقياس (ن=0 ؛ ) \\
\hline
\end{tabular}

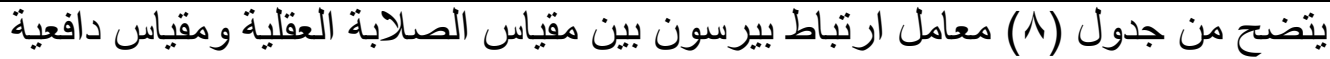

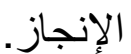

حيث بلغت قيمة معامل ارتباط بيرسون بين مقياس الصلابة العقلية ومقياس دافعية الإنجاز

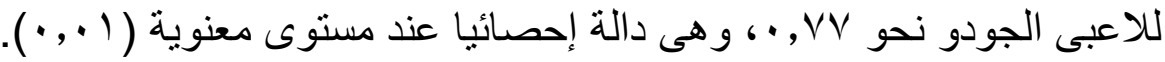

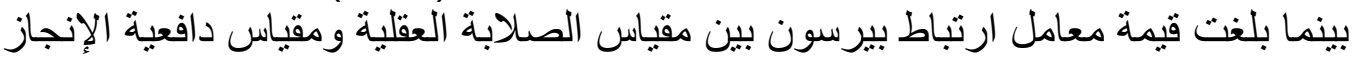

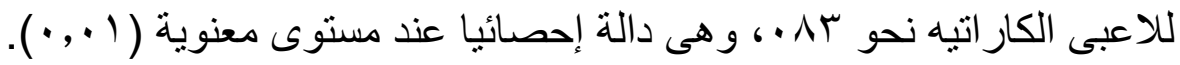

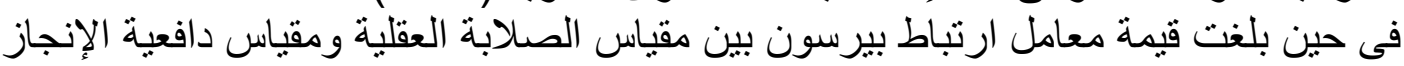

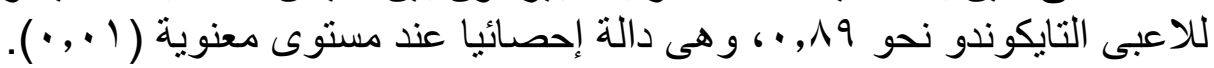

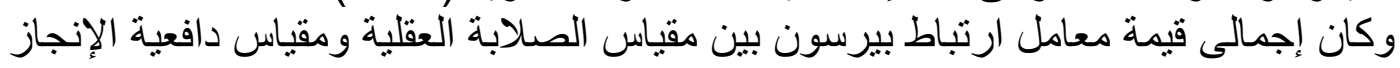

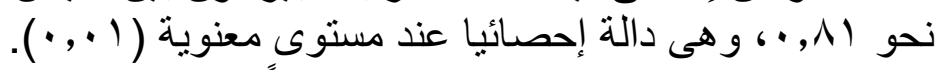

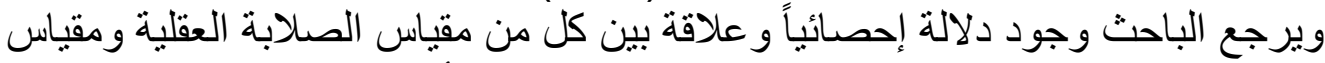

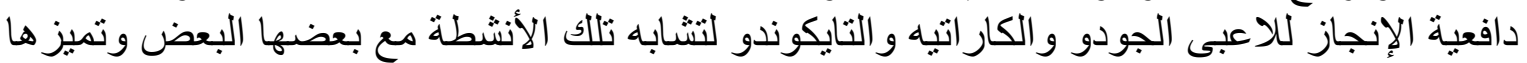

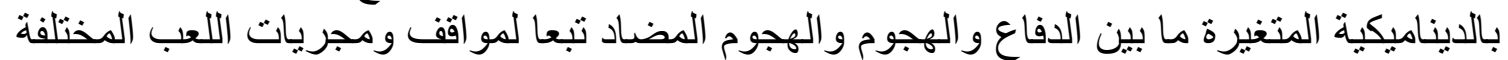

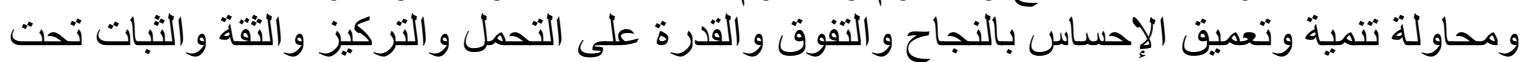

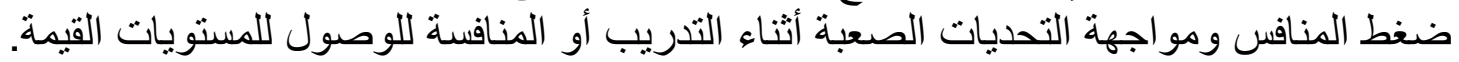

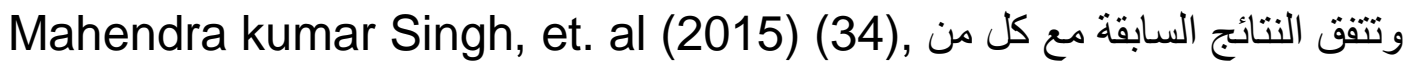

Bull SJ, et. al (2005) (22), Crust L, et. Al, (2005) (25), Nicholls AR, et. فى ارتباط محاور الصلابة العقلية من al (2005) (38), Golby J, et. al (2003) (27),

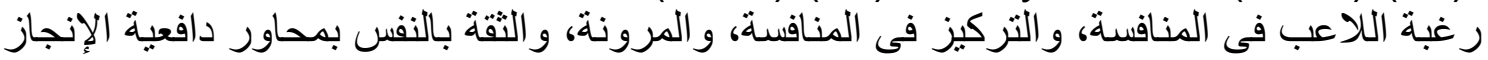

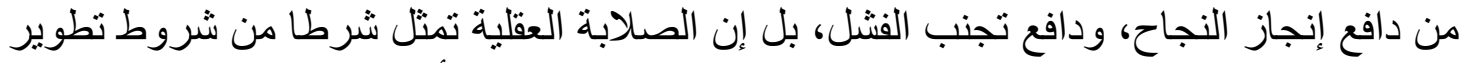

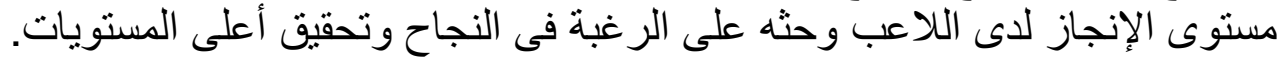

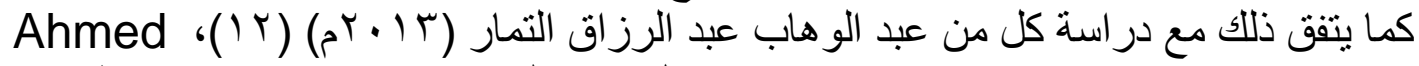

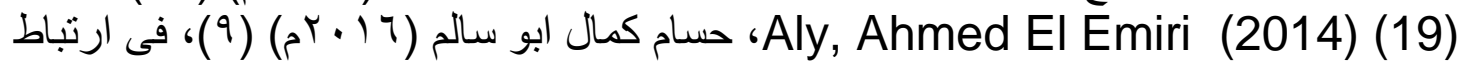

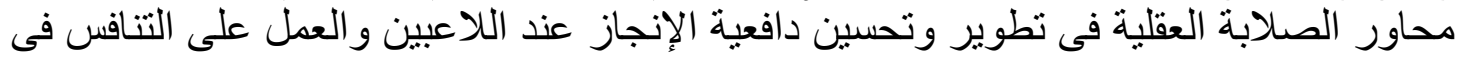

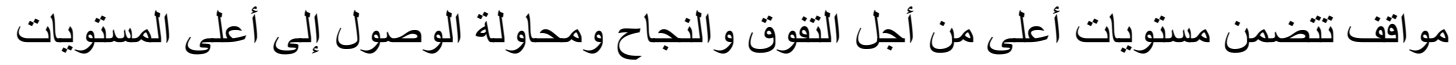

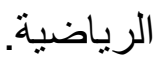

وبذلك تمت الأجابة على التساؤل الثالث و الذى ينص على ما العلاقة بين الصلابة العقلية

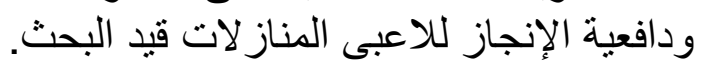

ــ التعرف على الفروق بين الصلابة العقلية ودافعية الإنجاز للاعبى المناز لات قيد البحث:-

جدول (9) جن (9)

منوسط الرتب واختبار Kruskal-Wallis لمحاور المقياسين

\begin{tabular}{|c|c|c|c|c|}
\hline مستوى الدلالة & Kruskal- & متوسط الرتب & |المناز لات & محاور الدقياسين \\
\hline
\end{tabular}




\begin{tabular}{|c|c|c|c|c|}
\hline & Wallis & & & \\
\hline \multirow{3}{*}{$\cdot, \times 1$} & \multirow{3}{*}{$\cdot, \vee$. } & $r \cdot, V V$ & الجودو & \multirow{3}{*}{ الصحلابة العقلية الأول لمقياس } \\
\hline & & $Y \leq, Y$. & الكار اتيه & \\
\hline & & $r \varepsilon, \cdot r$ & التابكوندو & \\
\hline \multirow{3}{*}{$\cdot, \cdot 1$} & \multirow{3}{*}{$0, \cdot r$} & $17, \wedge \mathrm{V}$ & الجودو & \multirow{3}{*}{ الصحور الثانى لمقياس العقلية } \\
\hline & & ro, $9 \mathrm{~V}$ & الكار اتيه & \\
\hline & & $r 7,1 V$ & التايكو ندو & \\
\hline \multirow{3}{*}{$\cdot, \vee}$. & \multirow{3}{*}{$\cdot, V Y$} & Y $1,0$. & الجودو & \multirow{3}{*}{ الصحلابة العقلية الثالث لمقياس } \\
\hline & & $r Y, Y M$ & الكار اتيه & \\
\hline & & YO, YV & التابكوندو & \\
\hline \multirow{3}{*}{$\cdot, \wedge$. } & \multirow{3}{*}{$\cdot, \leqslant 7$} & $r T, 0$. & الجودو & \multirow{3}{*}{ الصحلابة العقلية المقابع لمقياس } \\
\hline & & 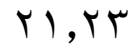 & الكار اتيه & \\
\hline & & $Y \varepsilon, Y V$ & التايكو ندو & \\
\hline \multirow{3}{*}{$\cdot, 99$} & \multirow{3}{*}{ r } & rY,T. & الجودو & \multirow{3}{*}{ دافعية الإنجاز الأول لمقياس } \\
\hline & & $r \mu, \varepsilon$. & الكار اتيه & \\
\hline & & $r r, \ldots$ & التايكو ندو & \\
\hline \multirow{3}{*}{$\cdot, 0$} & \multirow{3}{*}{$1, \xi}$. & $r 1, \ldots$ & الجودو & \multirow{3}{*}{ المحور الثانى لمقياس الإنجاز } \\
\hline & & $r I, V V$ & الكار اتيه & \\
\hline & & r & التايكوندو & \\
\hline
\end{tabular}

يتضح من جدول (9) منوسط الرتب وقيمة Kruskal-Wallis (كيرسكال ويلز) لمحاور مقياس الصعابِة العقلية ودافعية الإنجاز.

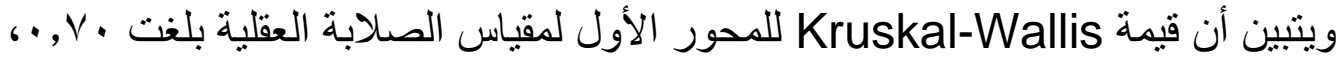

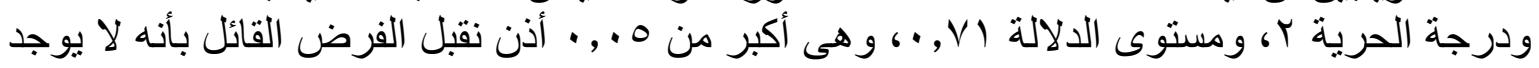
اختلاف بين لاعبى الجودو و الكار اتيه و التايكوندو.

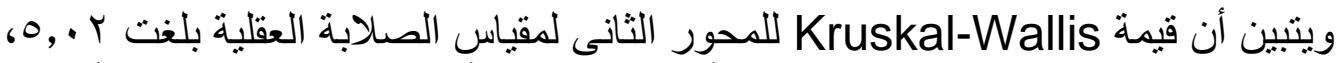

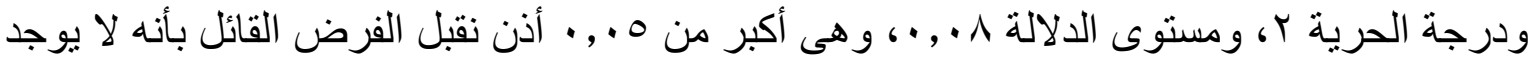
اختلاف بين لاعبى الجودو و الكار اتيه و التايكوندو.

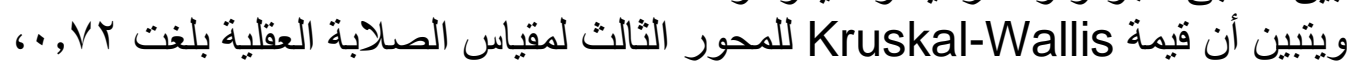

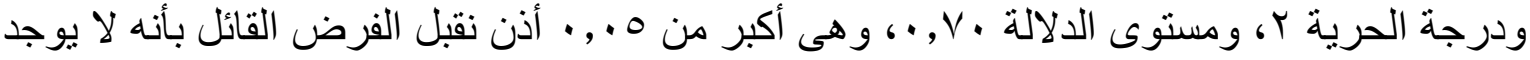
اختلاف بين لاعبى الجودو و الكار اتيه و التنايكوندو.

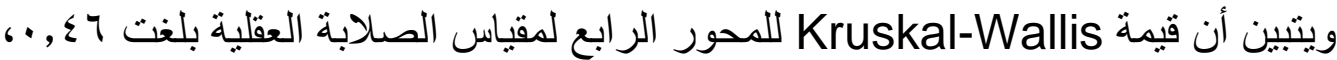

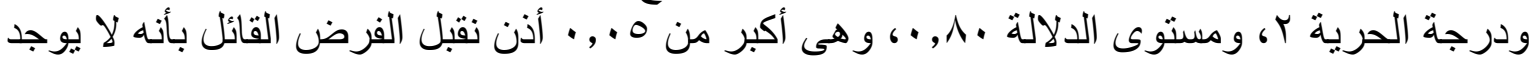
اختلاف بين لاعبى الجودو و الكار اتيه و التايكوندو.

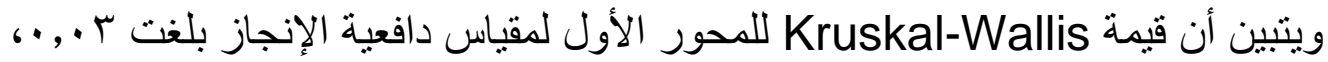

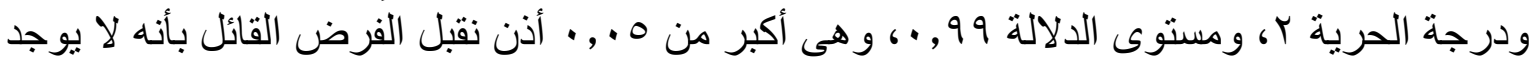
اختلاف بين لاعبى الجودو و الكار اتيه و التايكوندو. 


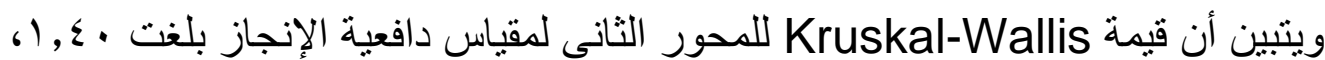

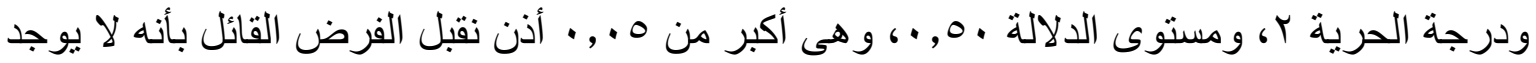
اختلاف بين لاعبى الجودو و الكار اتيه و التايكوندو.

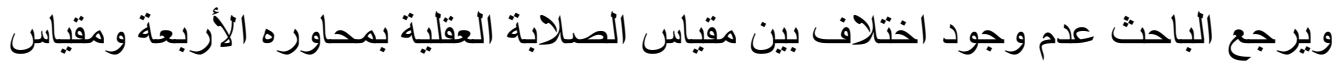

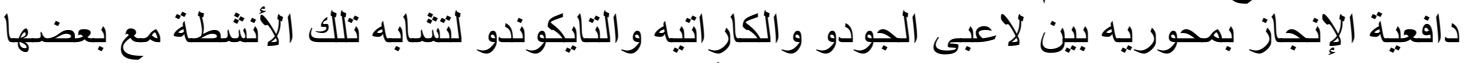

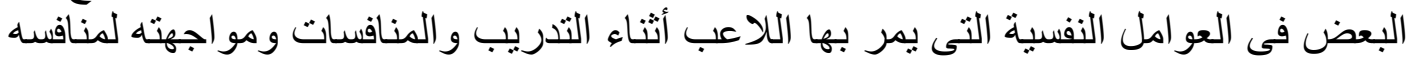

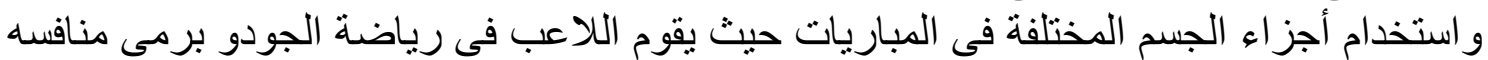

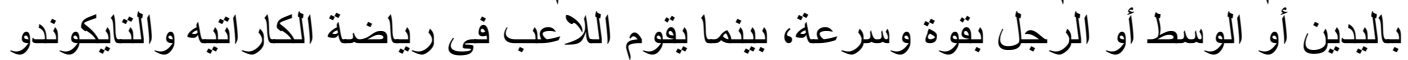

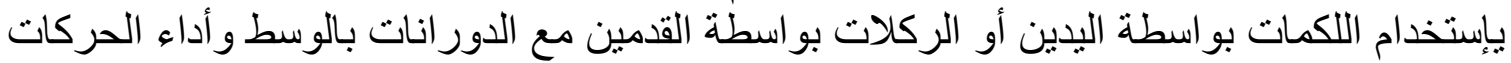

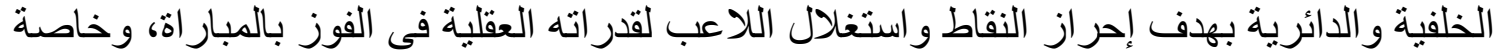
عند تقارب المستوى بين اللاعبين فى جوان النب الإعداد الأخرى.

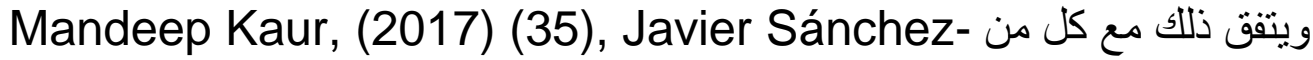

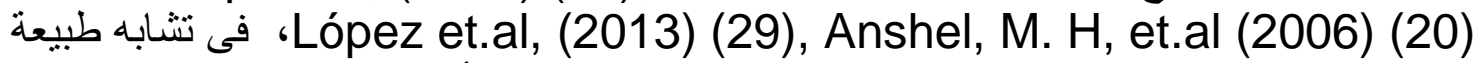

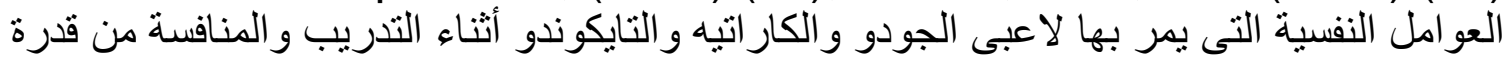

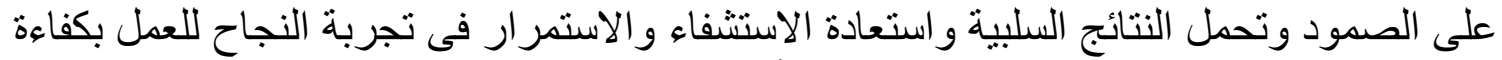

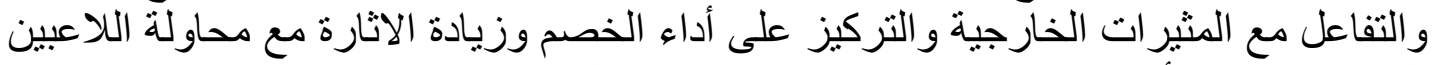

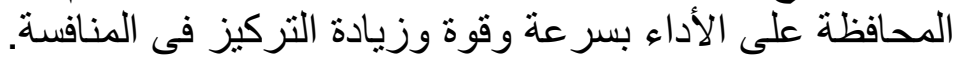

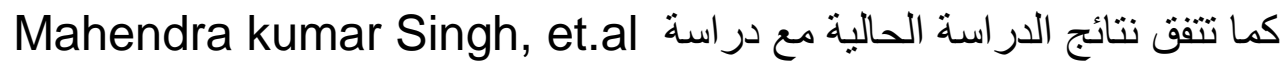

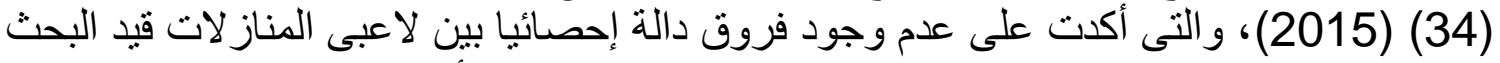

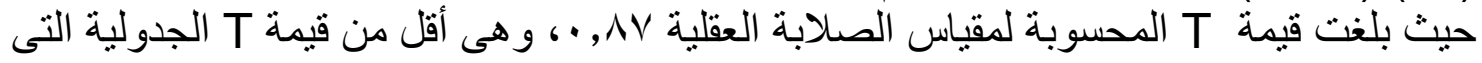

وبذللك تمت الأجابة على التساؤل الر ابع و الذى ينص على هل توجد فروق بين الصلابة

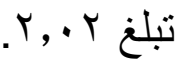
العقلية ودافعية الإنجاز للاعبى المناز لات قيد البحان الربح.

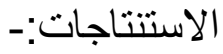

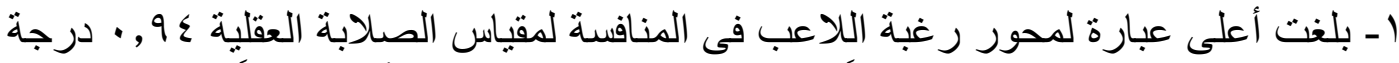
متوسطة وكانت لعبارة الاستمتاع حقاً بلذة الاشتثر الك فى المنافسة، وأقاتل دائماً للفوز فى كل دقية ديقة فى دئ المنافسة.

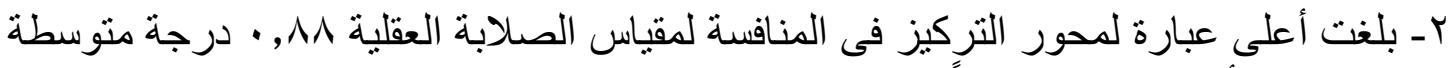

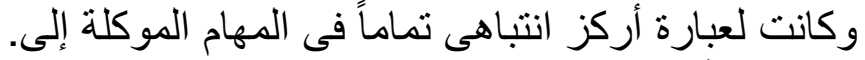

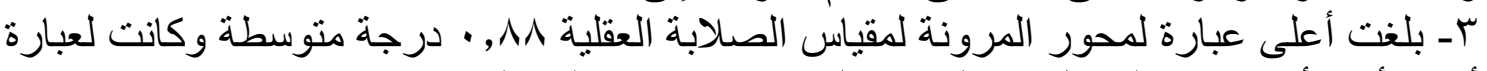

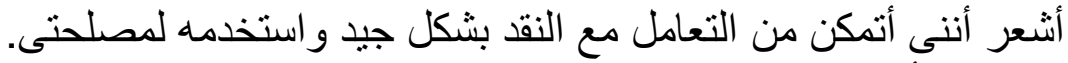

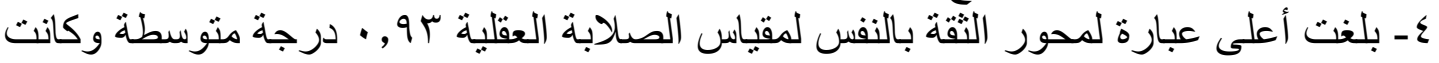

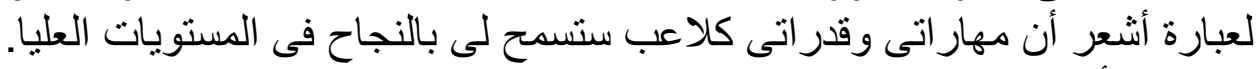

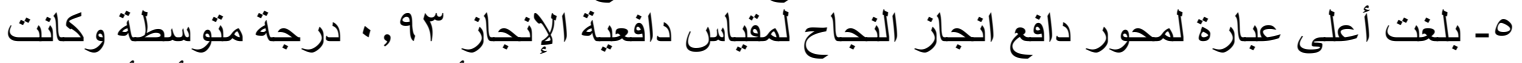

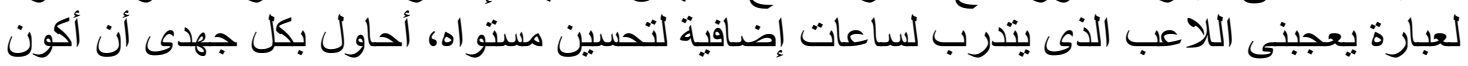

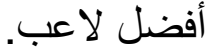

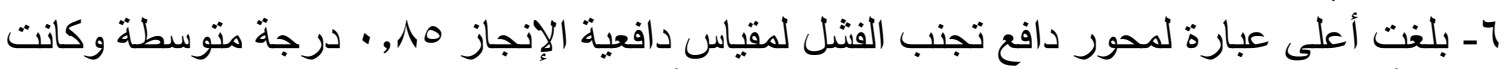

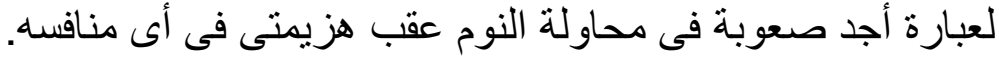

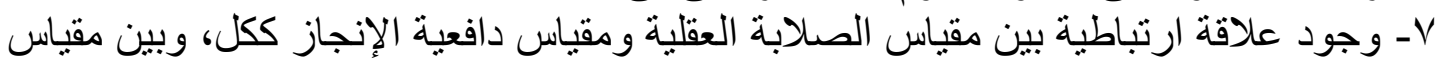

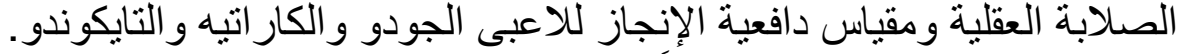

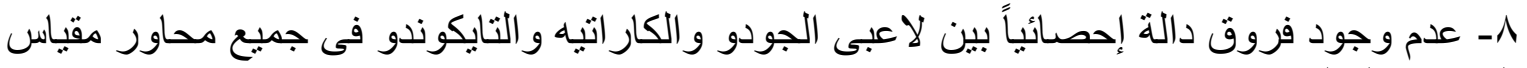
الصلابة العقلية، ودافعية الإنجاز. 


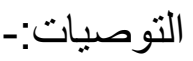

ا ـ تطبيق مقياس الصلابة العقلية ودافعية الإنجاز بمحاور هم المختلفة على لاعبى الأنشطة النز الية.

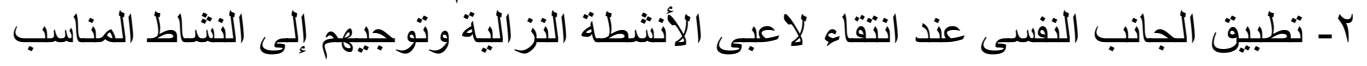
لاستعدادتهم النفسية. r- تو اجد المعد النفسى الرياضى مع لاعبى الأنشطة النز الية المختلفة بشكل دورى ومستمر خلال مر احل الإعداد المختلفة وكذلك أثناء البطو لات لتنمية وتطوير وصقل المظاهر النفسية التى يمر بها اللاعبين. عـ الأهتمام بالجوانب النفسية وخاصة مهار ات الصلابة العقلية ودافعية الإنجاز عند وضع البر امج التدريبية المختلفة. ــ تطبيق مقياس الصلابة العقلية ودافعية الإنجاز على أنثطة نز الية أخرى و أنشطة جماعية وفردية لمحاولة معرفة ما يتميز به كل نشاط من الأنشطة. 


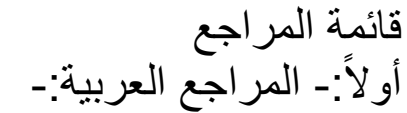

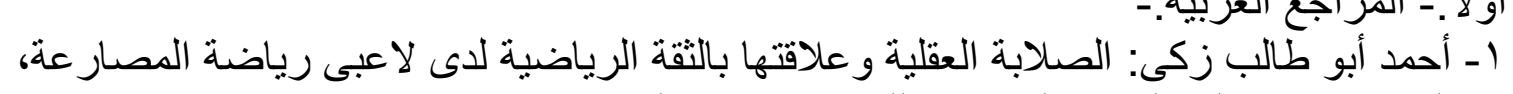

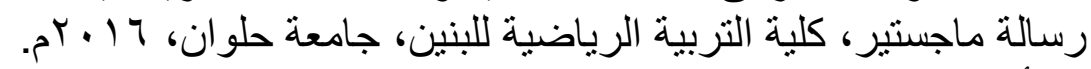

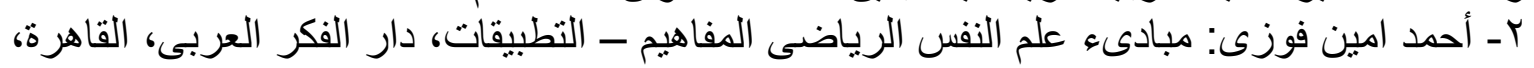
T. T بـ أحمد سعيد زهر ان: القو اعد العلمية و الفنية لرياضة التايكوندو، طس، دار الكتب المصرية،

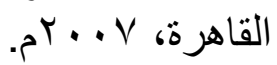
ع ـ أحمد سعيد زهر لهران: خصائص الطلاقة النفسية للاعبى المنتخب الكويتى للتايكوندو، در اسة تحليلية مقارنة، المجلة العلمية للتربية البدنية والرياضة، كلية التربية الرياضية للبنين، جامعة حلوان، إبريل . . . 1

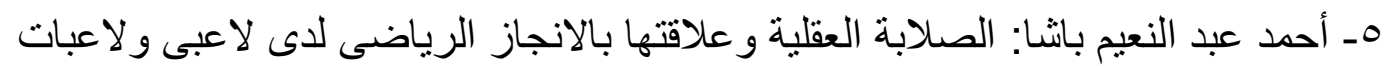

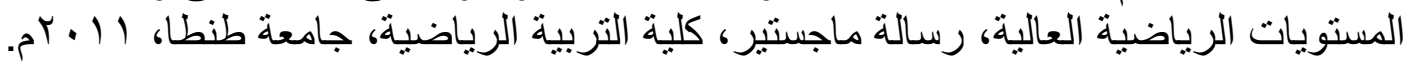

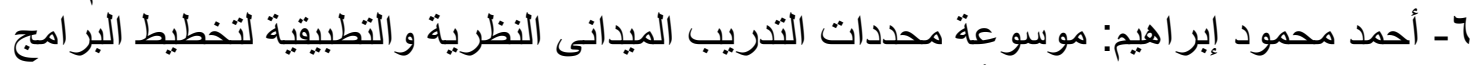

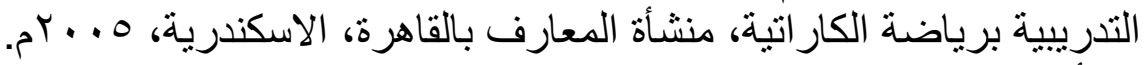

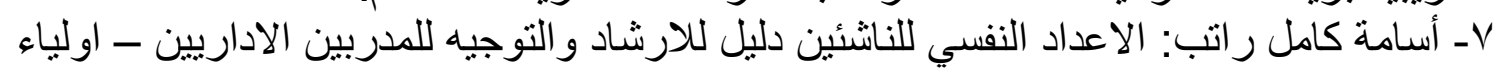

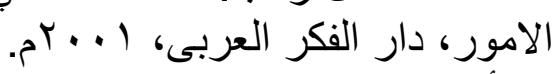

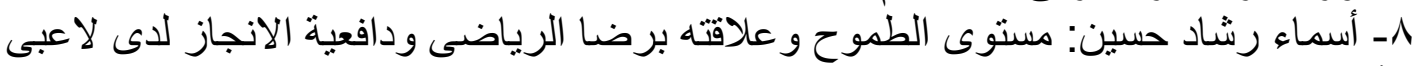

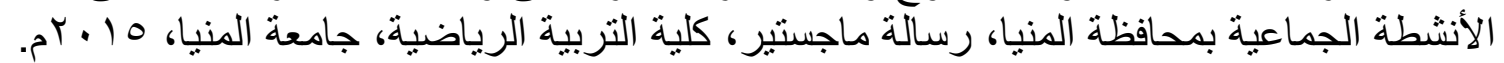

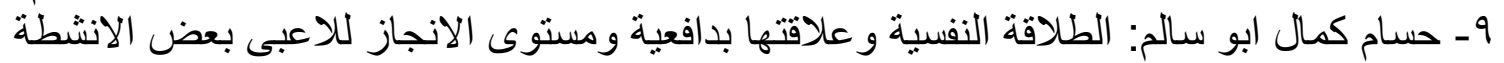

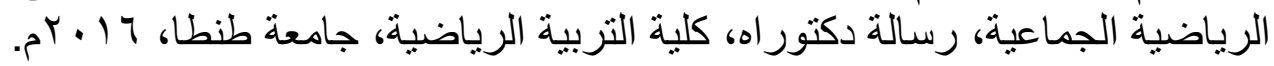

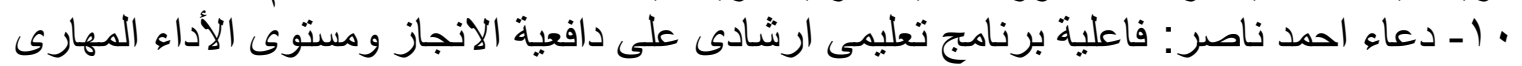

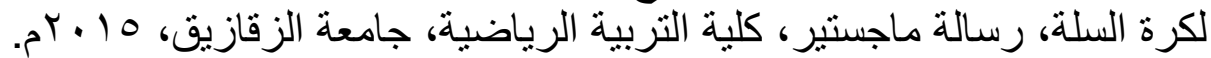

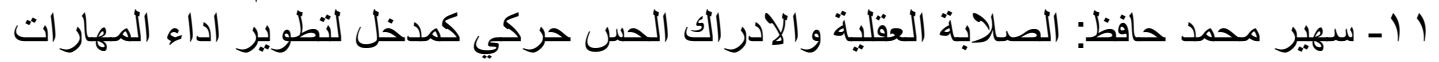

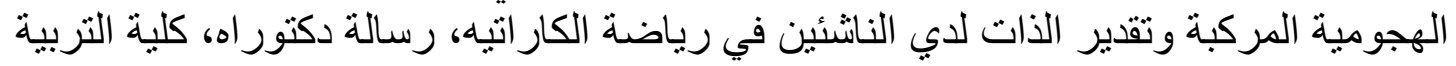

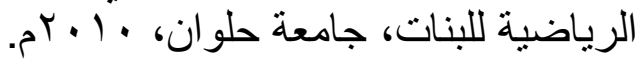

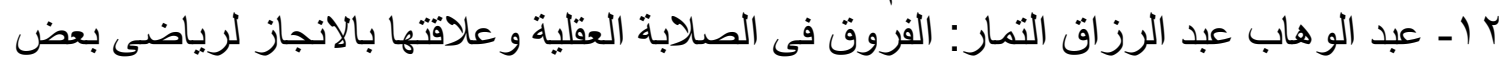

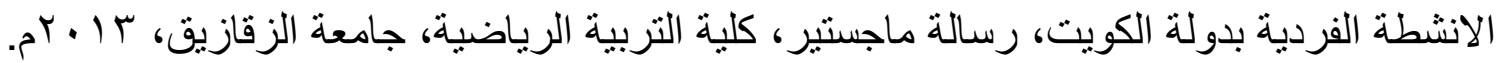

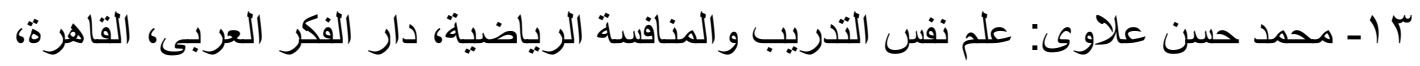

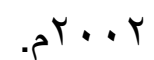
ع ا ـ محمود عبد الفتاح عنان، مصطفى حسين باهى، مقدمة فى علم نفس الرياضة، مركز الكتاب

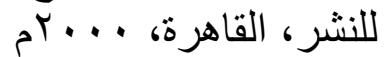

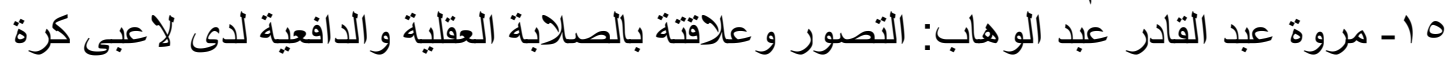

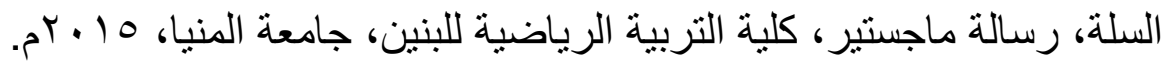

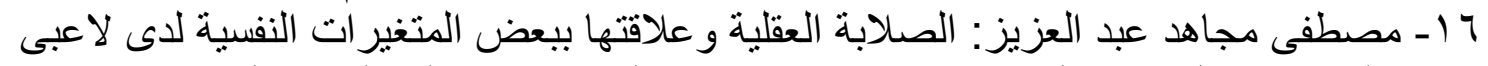

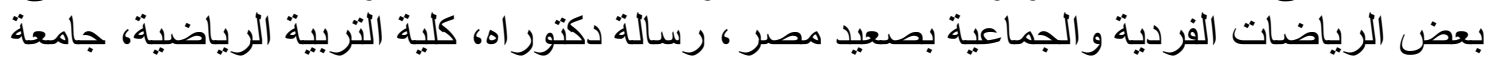

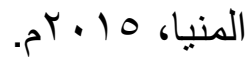
V ا ـ نجلة عبد المنعم بحيرى: برنامج مقترح بإستخدام تدريبات الصلابة العقلية على مستوى الإنجاز

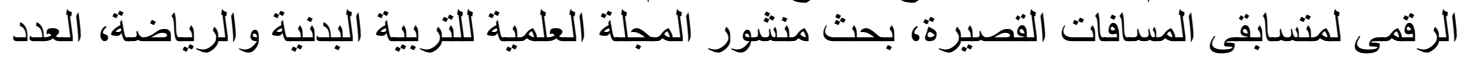

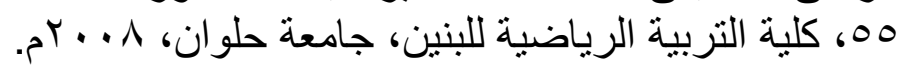

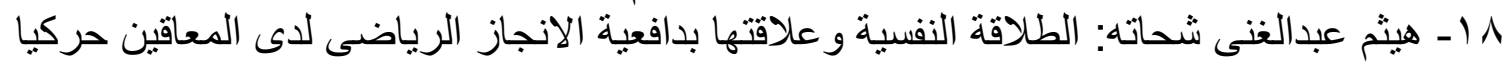

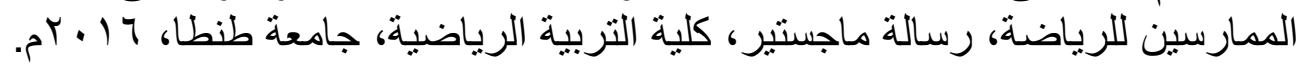




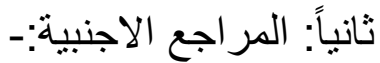

19- Ahmed Aly, Ahmed Alemiri: Mental Toughness and its Relationship to the Achievement Level of the Weightlifters in Egypt,

Turkish Journal of Sport and Exercise http://selcukbesyod.selcuk.edu.tr/sumbtd/index - Volume: 16 - Issue: 2

- Pages: 63-69 DOI: 10.15314/TJSE.201428107, 2014.

20- Anshel, M. H., \& Payne, J. M.: Application of sport psychology for optimal performance in martial arts. In J. Dosil (Ed.), The sport psychologist's handbook. A guide for sport-specific performance enhancement (pp. 353-374). Inglaterra: John Wiley \& Sons, 2006. 21- Asamoah B. The role of mental toughness, psychological skills and team cohesion in soccer performance. Master thesis, Stellenbosch University, Faculty of Education, 2013.

22- Bull, J. Shambrook, Will James, E. Brooks: Towards an Understanding of Mental Toughness in Elite English Cricketers, Journal of Applied Sport Psychology, Volume 17, 209-277, 2005. 23- Cherry, Heather Leanne: Psychometric Analysis of an Inventory

Assessing Mental Toughness, Master's Thesis, University of .Tennessee, http://trace.tennessee.edu/utk gradthes/588, 2005

24- Cory S. Middleton: Mental Toughness, Conceptualisation and Measurement, A thesis submitted to the School of Psychology, University of Western Sydney, S. C. Middleton, 2007. 25- Crust L, Clough PJ: Relationship between mental toughness and physical endurance, Perceptual and Motor Skills; 100: 192- 194, 2005.

26- Daniel F. Gucciardi , Sandy Gordon \& James A. Dimmock: Evaluation of a Mental Toughness Training Program for Youth-Aged Australian Footballers: I. A Quantitative Analysis, Pages 307-323, 2009.

27- Golby J, Sheard M, Lavallee D: A cognitive - behavioral analysis of mental toughness in national rugby league teams. Perceptual and Motor Skills, 96: 455-462, 2003. 28- Gucciardi, D. F., Jackson, B., Hodge, K., Anthony, D. R., \& Brooke, L. E: Implicit theories of mental toughness: Relations with cognitive, motivational, and behavioural correlates. Sport, Exercise, And Performance Psychology, 4(2), 100-112, (2015). 29- Javier Sánchez-López, Thalía Fernández, Juan Silva-Pereyra, Juan Antonio Martínez Mesa: Differences between Judo, Taekwondo and Kung-fu Athletes in Sustained Attention and Impulse Control, Psychology , 2013, Vol.4, No.7, 607-612, 2013.

30- Jones $G$, Hanton $S$, Connaughton $D$ : What is this thing called mental toughness? An investigation of elite sport performers. Journal of Applied Sport Psychology, 14(3), 205- 218, 2002. 
31- Karen, A: Mental Toughness: Brain Power for Sports, Ebsco

publishing, 2002.

32- Kudlackova k: The Relationship between mental toughness, relaxation activities, and sleep in athletes at different skill levels,

Electronic theses, The Florida State University, 2011.

33- Luke Maher: A comparative study of self-esteem, mental toughness and athletic identity in team and individual sports: male athletes, BA (Hons) Psychology, National College of Ireland, 2016. 34- Mahendra kumar Singh, Arjun singh Solanki: Analysis of Mental

Toughness and Mental Health of Tae-Kwon-Do and Judo Players,

International Journal of Applied Research; 1(9): 507-510, 2015.

35- Mandeep Kaur: Analysis of mental toughness among the players of five different contact sports groups, International Journal of Physical

Education, Sports and Health, 4(4): 451-452, 2017.

36- Marcos Filipe Guimarães Pinheiro,André Gustavo Pereira de Andrade, Guilherme de Sousa Pinheiro, Franco Noce: Motivational dimensions of taekwondo practitioners, Arch Budo, VOLUME 11, 403:411, 2015.

37- Middleton SC, Marsh WH, Martin JA, Richards EG, Perry C:

Discovering mental toughness: A qualitative study of mental toughness in elite athletes. SELF Research Centre, University of Western Sydney, Australia, 2004.

38- Nicholls AR, Polman RJ, Levy AR, Backhouse SH: Mental toughness in sport: Achievement level, gender, age, experience, and sport type differences, Personality and Individual Differences; 47(1): 73-75, 2005.

39- Phairembam Jiteshwor, Nomgmaithem Sunderlal, Dr. S. Ranjit Singh, Hassan gharayagh zandi, Naorem Jinet Singh: Comparative study of the Sports Achievement Motivation between Male and Female School Basketball Players, IOSR Journal Of Humanities And Social Science (IOSR-JHSS)e-ISSN: 2279-0837, p-ISSN: 2279-0845. Volume 7, Issue 2, PP 23-26, www.losrjournals.Org (Jan. - Feb. 2013). 40- Radeke, T.D., \& Smith, A: Development and preliminary validation of athlete Burnout measure, Journal of sport \& exercise psychology, U.S.A, 281- 306, 2003.

41- Ramesh Chand Yadav: Comparative Study of Mental Toughness between National Female Volleyball and Kabaddi Players, Journal of Education and Practice www.iiste.org ISSN 2222-1735 (Paper) ISSN Vol.5, No.14, 2014.)2222-288X (Online

42- Simon C. Middleton, Herb W. Marsh, Andrew J. Martin, Garry E. Discovering Mental Toughness: A :Richards, and Clark Perry Qualitative Study of Mental Toughness in Elite Athletes, SELF Research Centre, University of Western Sydney, Australia, 2004. 
43- TaeHee Lim, David Michael O'Sullivan: Case Study of Mental Skills Training for a Taekwondo Olympian, Journal of Human Kinetics volume 50/2016, 235-245 DOI: 10.1515/hukin-2015-0161Section IV Behavioural Sciences in Sport, 2016. ثالثاً: مراجع شبكة المعلومات الدولية (الانترنت):44- https://www.ijf.org/history, January, 2017. 45- https://www.wkf.net/ksport-rules-regulations.php, January, 2017. 46- http://www.worldtaekwondo.org/about-wt/about-wt/, January, 2017. 
مستخلص البحث

الصلابة العقلية و علاقتها بدافعية الإنجاز لبعض لاعبى أنشطة المناز لات

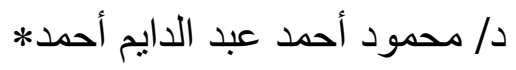

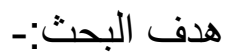

يهدف البحث إلى تحديد العلاقة بين الصلابة العقلية ودافعية الإنجاز لبعض لاعبى أنشطة

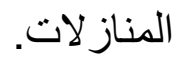

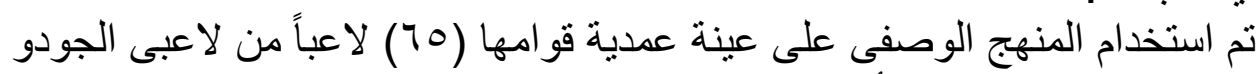

منهج و عينة البحث:- الات

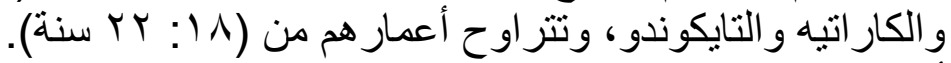

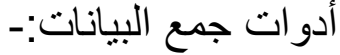

- مقياس الصلابة العقلية. مقياس دافعية الإنجاز .

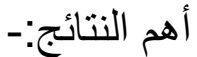

ا ـ التعرف على مستوى الصلابة العقلية ودافعية الإنجاز للاعبى الجودو و الكار اتيه و التايكوندو.

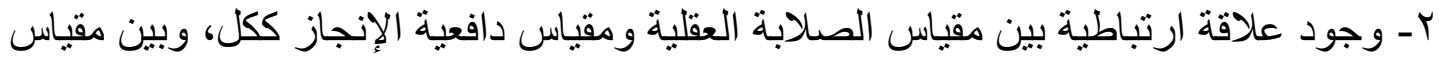

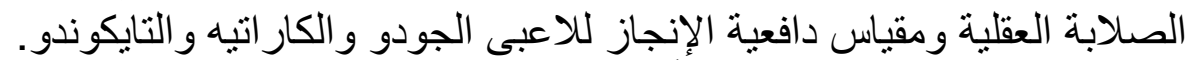

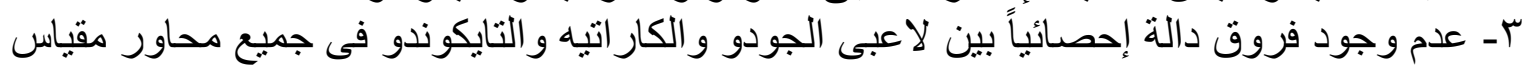

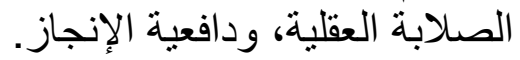

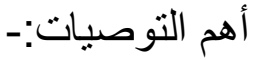

ا - تطبيق مقياس الصلابة العقلية ودافعية الإنجاز بمحاور هم المختلفة على لاعبى الأنشطة النز الية.

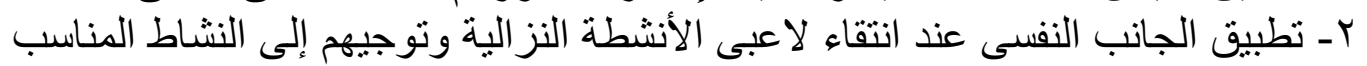
لاستعدادتهم النفسية.

بـ تو اجد المعد النفسى الرياضيى مع لاعبى الأنشطة النز الية المختلفة بشكل دورى ومستمر خلال مر احل الإعداد المختلفة. ع ـ الأهتمام بالجو البب النفسية وخاصة مهار ات الصلابة العقلية ودافعية الإنجاز عند وضع البر امج التدريبية المختلفة. الكلمات المفتاحية:-

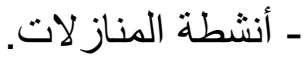

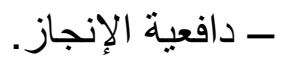

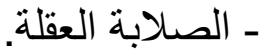

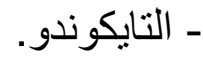

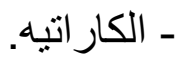

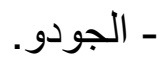

Abstract

The relationship between mental toughness and achievement motivation of some players in the activities martial arts

*Mahmoud Ahmed Abd El-Dayem Ahmed Saleh

The research aims:-

Email: mtaekwondayem@mans.edu.eg Mobile:+201060266191

"Lecturer Sport Training, Faculty of Physical Education, Mansoura University, Egypt

Email: mtaekwondayem@mans.edu.eg Mobile: +201060266191 
The research aims to determine the relationship between mental toughness and achievement motivation of some of the activities martial

arts.

Methodology and Sample Research: -

The descriptive curriculum was used on a deliberate sample of

65 players of judo, karate and taekwondo, aged from (18:22 years).

Data collection tools: -

- Mental toughness measure. - Achievement motivation measure.

The most important results:-

1- To learn about the level of mental toughness and achievement motivation of the players in judo, karate and taekwondo.

2- There is a correlation between the measure of mental toughness and the measure of achievement motivation as a whole, and between the measure of mental toughness and the measure of achievement motivation of the judo, karate and taekwondo players.

3- There are no statistically significant differences between judo, karate and taekwondo players in all the axes of the mental toughness measure, and the achievement motivation.

The most important recommendations:-

1- Application of the measure of mental toughness and achievement motivation with their different axes to the players of the martial arts.

2- Applying the psychological aspect of selecting the players and guiding them to the appropriate activity for psychological use.

3- The presence of the sports psychologist with the players of various different martial arts activities periodically and continuously during the various stages of preparation.

4- Attention to the psychological aspects, in particular the skills of mental toughness and achievement motivation in the development of the various training programmes.

The heads of relevant topics:-

- Mental toughness.

- Achievement motivation.

- Martial arts. - Judo.

- Karate.

- Taekwondo. 